\title{
النظرية النسوية ودراسة التفاوت الاجتماعى
}

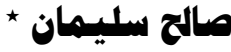

يحاول البحث الراهن التعرف على النظريات النسوية المختلفة فى ضوء تلتاولها للتفاوتات الاجتماعية

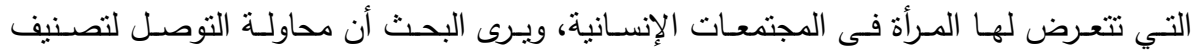

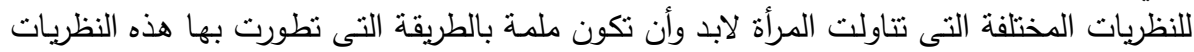

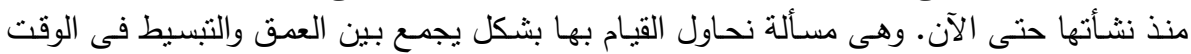

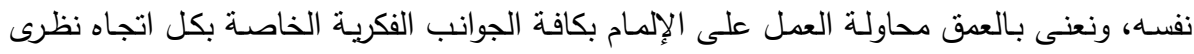

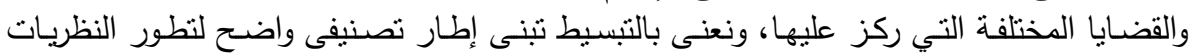

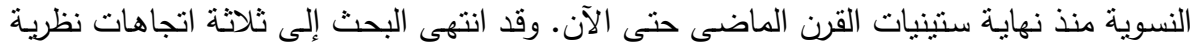
تثمل النظريات النسوية الإصلاحية والنسوية المقاومة وأخيرا النسوية المتمردة.

\section{هقدهة}

يوجد العديد من النظريات النسوية المختلفة التى حاولت أن ترصد مظاهر التفاوتات المختلفة بين الرجل والمرأة فى المجتمعات البشرية، وبشكل خاص أوضاع المرأة فى الغرب. واللافت للنظر أن معظم هذه النظربات ظهرت فى العالم الغربى منذ الثورة الصناعية حتى الآن؛ بمعنى آخر فإن هذه النظريات ارتبطت بالأساس بالسياقات الغربية ودرجة النظور الذى وصلت إليه مجتمعاتها. وتتسم هذه النظريات بشكل عام بمحاولة تشخيص أوجه التفاوت التى تواجه المرأة وبشكل خاص فى مجال العمل رغم

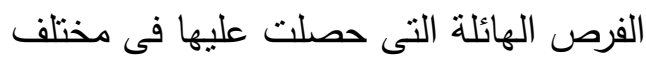
* أستاذ مساعد، كلية الآداب، جامعة عين شمس .

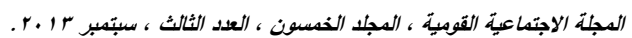


المجالات بما فى ذلك بعض المجالات التى لم يكن من المتصور أن تلتحق بها. وما

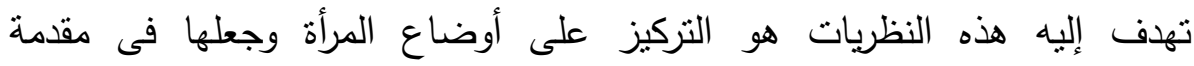

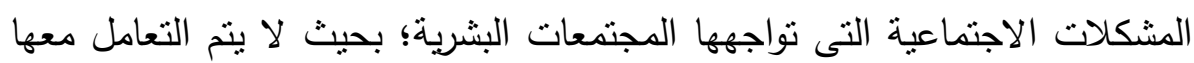

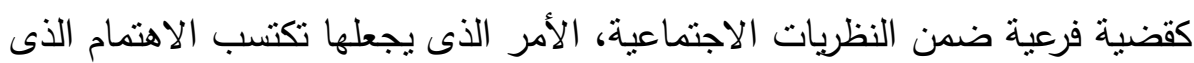

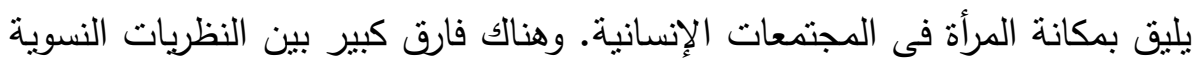
القديمة النى كانت تتعامل مع قضايا المرأة كعنصر وحيد وبين النظريات الحديثة

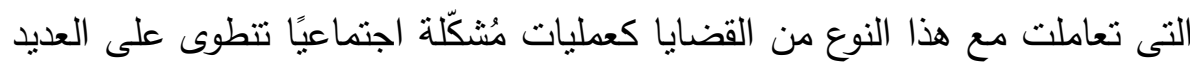

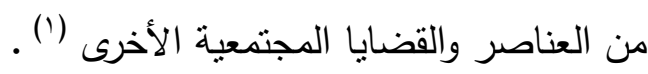
وتعود الاختلافات الرئيسة بين الرجل والمرأة إلى الاختلاف فى طبيعة الخبرات

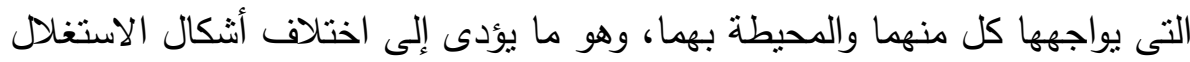

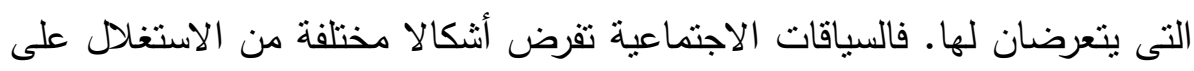

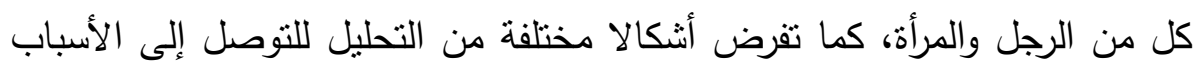
المؤدية لهذه التفاونات. ويُعد استغلال النساء القاسم المشترك بين هذه النظريات كافة التهات

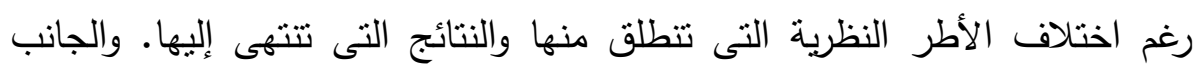

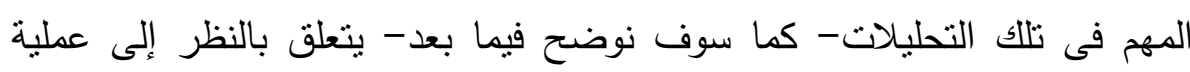

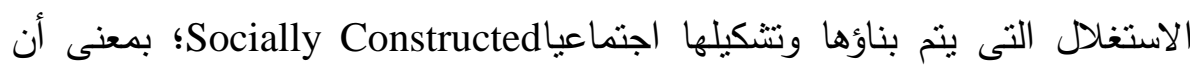

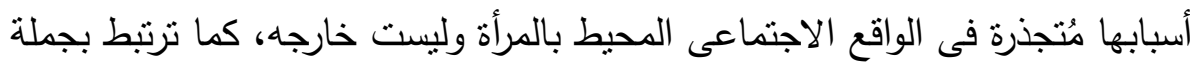

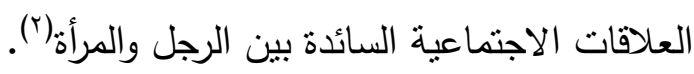
والملاحظ هنا أن كل نظرية نسوية تشتمل على بعض النظريات التى تسبقها

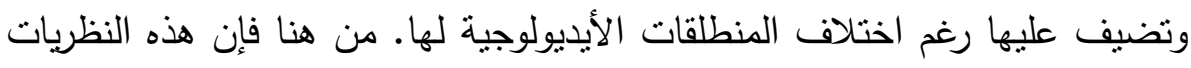

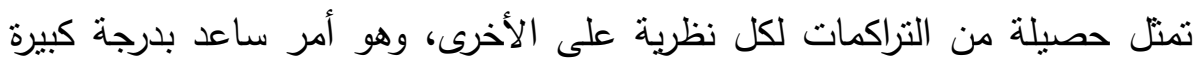

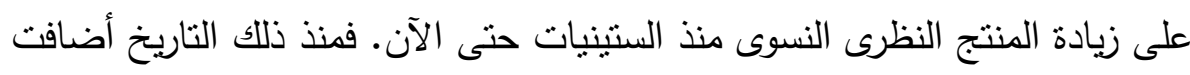

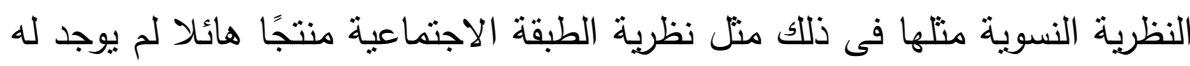

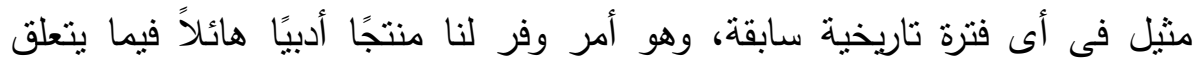


بنظريات المرأة. ومن المعلوم، كما سوف نوضح لاحقا، أن نظريات المرأة قد بدأت

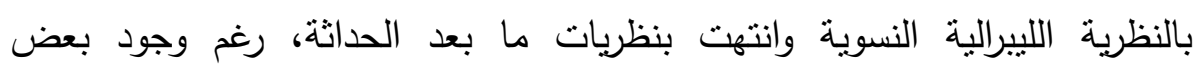
التحليلات السيكولوجية السابقة على ذلك. ورغم بعد الثقة بين ما بدأته هذه النظريات

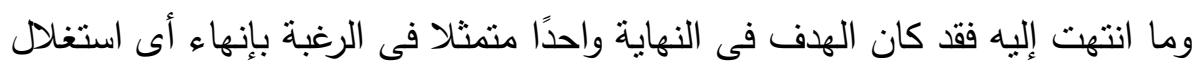

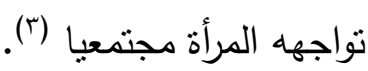

إن محاولة التوصل لتصنيف النظريات المختلفة التى تتاولت المرأة لابد وأن

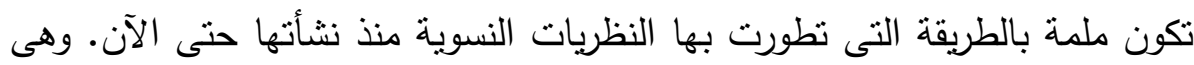

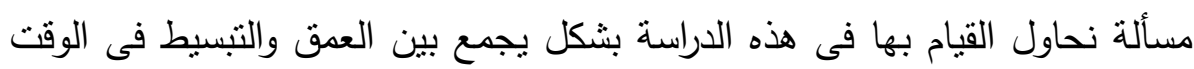
نفسه. ونعنى بالعمق محاولة العمل على الإلمام بالجوانب الفكرية الخاصة بكل اتجاه

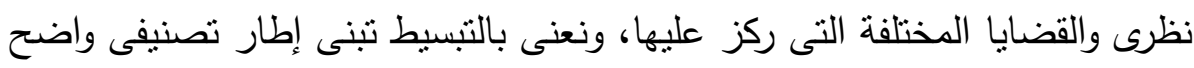

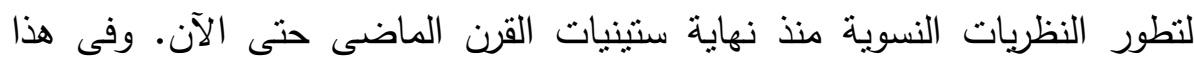

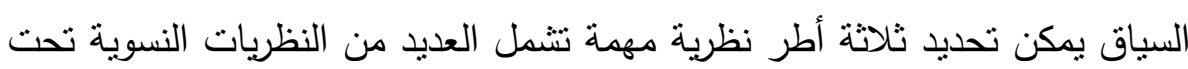
مظلتها هى:

1- النظريات النسوية الإصلاحية Gender Reform Feminism، وهى تركز بشكل رئيس على عمل النساء فى الأسرة والاقتصاد ككل، ومحاولة التوصل لأثكال

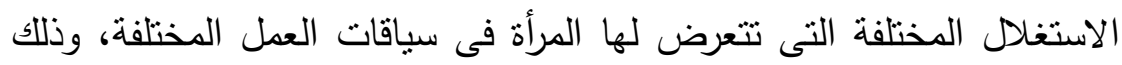
من أجل تحسين ظروفها والارتقاء بأوضاعها المعيشية.

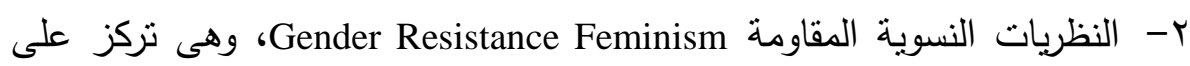
العنف والقهر الجنسى الموجه ضد النساء، وعلى استخدام خبرات النساء بوصفها عنصرا مركزيا بالنسبة للمعرفة والثقافة المجتمعية، أى نقلها من حيز

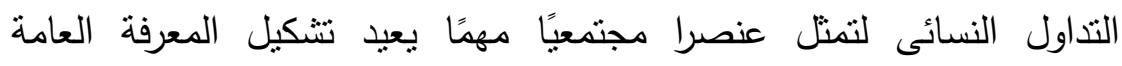

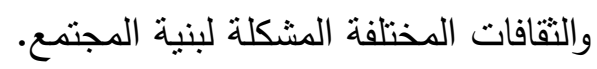
r- النظريات النسوية المتمردة Gender Rebellion Feminism، وهى تزكز على

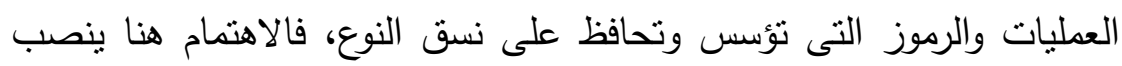


على ما تقوله المرأة ذاتها ومحاولة الإعلاء من شأنها مجتمعيا، بحيث لا تخضع للخطاب الذكورى السائد والمهيمن. وسوف نتتاول كل اتجاه من الاتجاهات السابقة بشكل أكثر تفصيلا بما يساعد على تحديد الجوانب النظرية الخاصة به.

\section{الرؤية المنهبية وإشكالية الدراسة}

تتطلق الدراسة الراهنة من توجه وصفى تحليلى؛ فهو وصفى من ناحية قيامه بالعمل

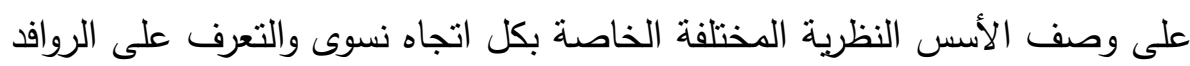
المختلفة المرتبطة بكل نبار نظرى وتحليلى من ناحية الوقوف على النطور النظرى الناه

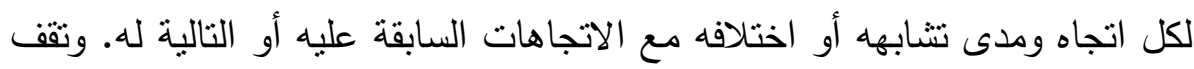
الدراسة على عدة قضايا تحليلية مثل طبيعة التفاوتات التى تقف عندها النظرية، وعمل المرأة والموقف منه، ورؤية المجتمع لقضية المساواة بينها وبين الرجل، وأخيرا طبيعة الحلول التى تطرحها تلك النظرية وكيفية مواجهة أنشال التفاوتات المختلفة فيما بينهما. وهنا يفرض التساؤل الرئيسى للاراسة نفسه: هل تتعامل النظريات

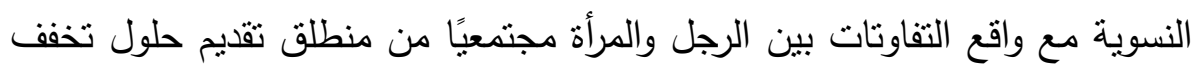

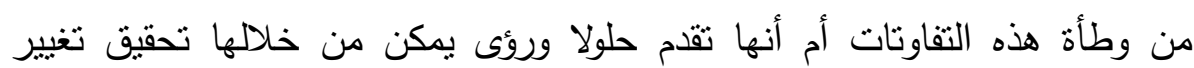
جذرى للمجتمع يؤدى لفرض المساواة بين الرجل والمرأةه.

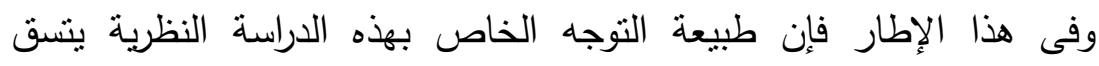
ورؤيتها لتعريف المقصود بالتفاوت الاجتماعى بين الرجل والمرأة والذى نقصد به أية الترالية قواعد اجتماعية أو أطر قانونية ونتريعية تقبل بالاستغلال الاجتماعى والسياسى الإجى

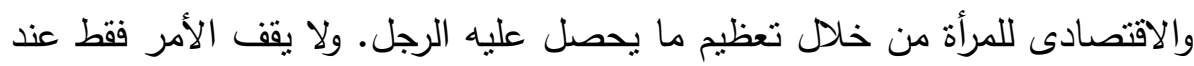
مستوى الممارسات الرسمية الخاصة بالدولة والمؤسسات والدنظمات التابعة لها لكنه

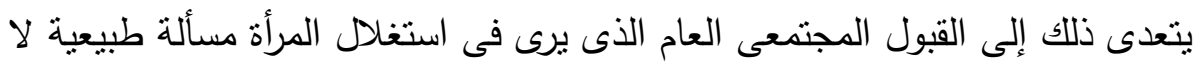

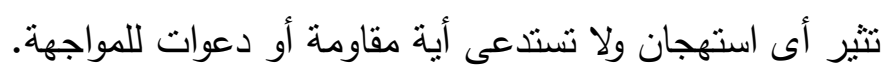


وفى ضوء ذلك فإن الدراسة الراهنة تهذف إلى التعرف على أهم الاتجاهات

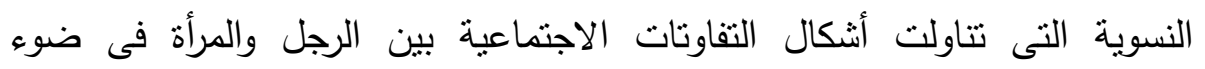
المحددات النظرية التى تتطوى عليها، وفى ضوء ما تقدمه من رؤى تساعد على التى

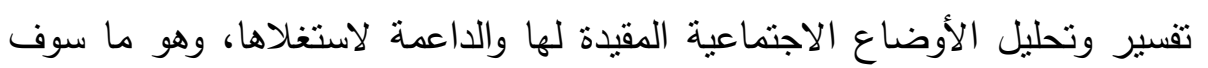

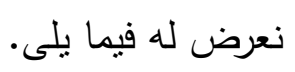

\section{أولا: النظريات النسوية الإصلاحية Gender Reform Feminism}

شأن كل النظريات الخاصة بعلم الاجتماع فإنها تتثأ فى البداية موجهة للإصلاح

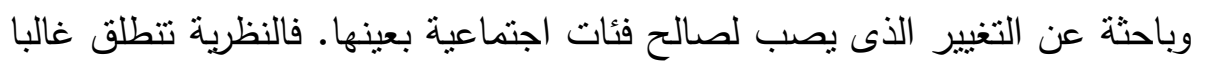

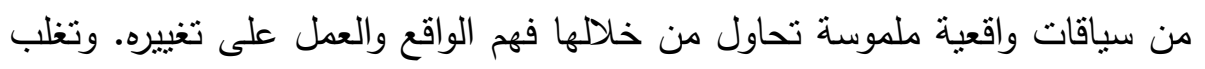

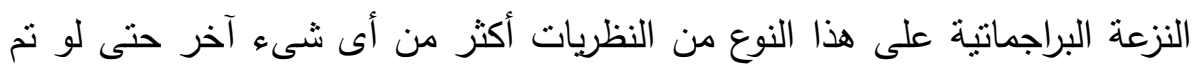

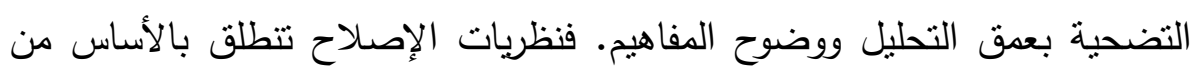

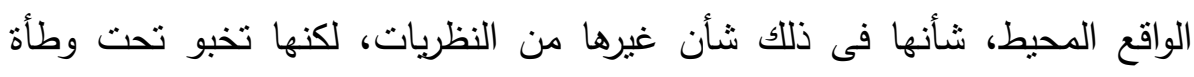

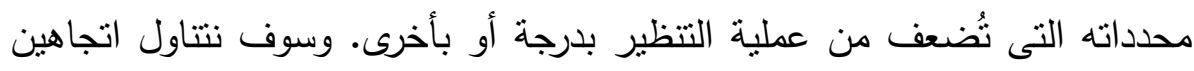

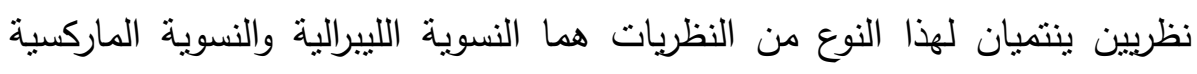

$$
\text { والاشتراكية. }
$$

Liberal Feminism النسوية الليبرالية

تنتمى النسوية الليبرالية إلى المفكرين الليبراليين الأوائل أمثال روسو ولوك وهوبز

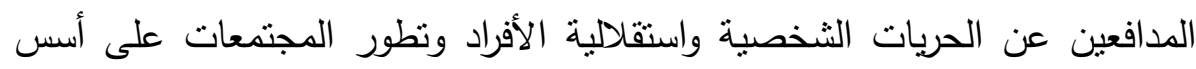

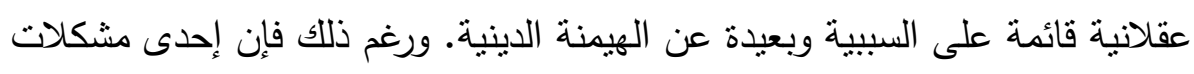

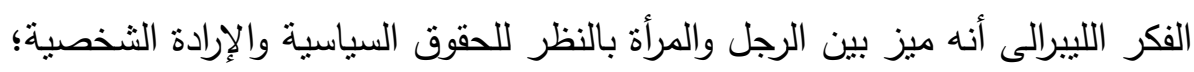

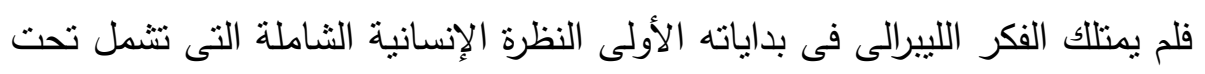

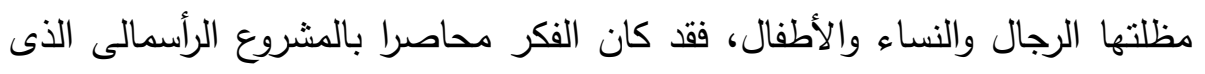

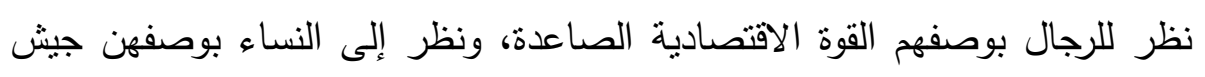

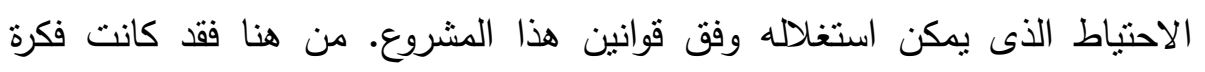


الحرية لاى الآباء الليبراليين المؤسسين فكرة تعنى حرية الرجال دون غيرهم. وفى هذا السياق، حاول بعض الفكرين الليبرالين المحدثين أمثال (جون سنتيورات ميل) استخدام مفهوم الحرية الثخصية لنطوير وضعية المساواة بين الرجل والمرأة، وبشكل خاص فيما يتعلق بالقدرات المتعلقة بالتملك والوصول إلى السوق؛ فقد ظلت الملكية وممارسة الأدوار المختلفة المرتبطة بها عاملا هاما فى نقييم حالة المساواة القائمة بين المرأة والرجل وفقا للمفكرين الليبراليين الدحدثين. وفى معالجتها للتفاوتات الاجتماعية التى نواجهها المرأة تتنقد النظرية الليبرالية التفاونات القائمة على الاختلافات البيولوجية بين الرجل والمرأة. وبشكل عام، فإن إنات النسويات الليبراليات يرين عدم أهية الفروق البيولوجية بين الرجل والمرأة فى الإني

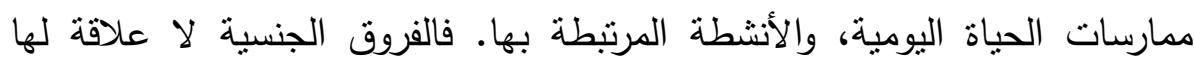

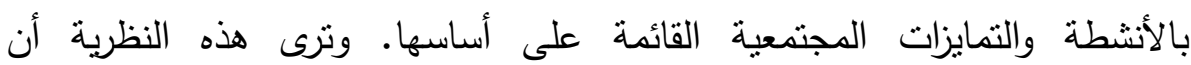
الاختلافات بينهما ليست كبيرة بما يستدعى تأسبس اختلافات فى الحقوق الخاصة بهما، وبالتالى تكريس أنماط من التفاوتات المجحفة للمرأة مقارنة بما يحصل عليه الرجل مجتمعيا. وتدحض هذه النظرية الاختلافات القائمة على الجنس بين الرجل

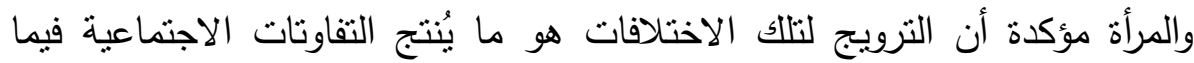
بينهما ويساعد على القبول المجتمعى لها. ومن منطلق رفض هذه النظرية اعتماد الفروق الجنسية بين الرجل والمرأة فإنها تدعو للتخلص من أنثال التمييز الاجتماعى لهن كافة بين الرجل والمرأة وبشكل خاص فى مجالى التعليم والعمل.

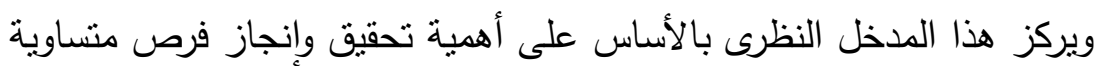

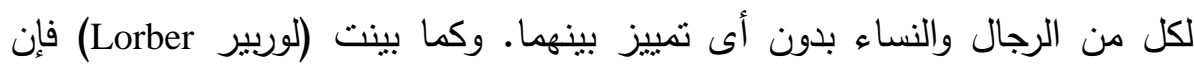

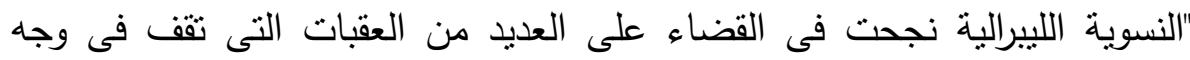
النساء فى الدخول إلى مجالات العمل النى كانت حكرا على الرجال، كما أنها لإلى

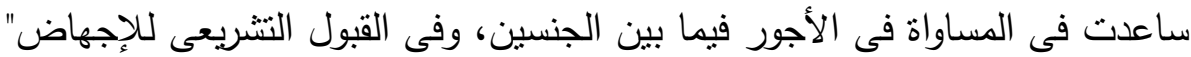

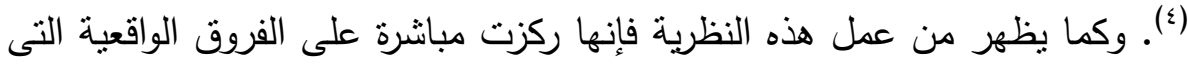


تواجه الررأة وبشكل خاص فى مسألة العمل والمساواة فى الأجر ؛ فمن غير المعقول

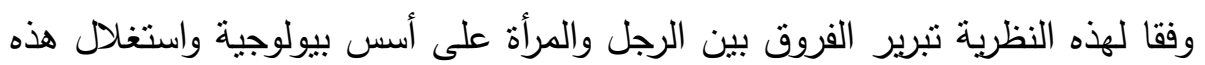
التصورات السلبية فى نكريس الفروق على مستوى الالتحاق بسوق العمل وما يرتبط بذلك من تفاوتات فى الدخل من ناحية، والحصول على مناصب أعلى من ناحية

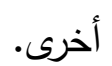
ولقد اعتمدت السياسات الليبرالية النسوية على حركة الحقوق المدنية فى

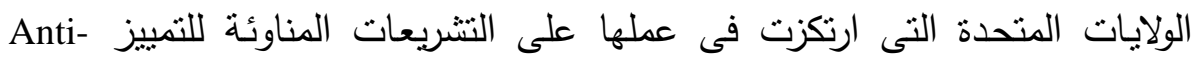
discrimination Legislation التفاوتات القائمة على النوع، وبشكل خاص نلك المستشرية فى سوق العمل والتعليم

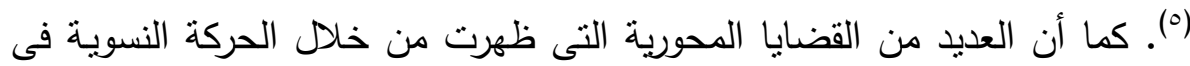

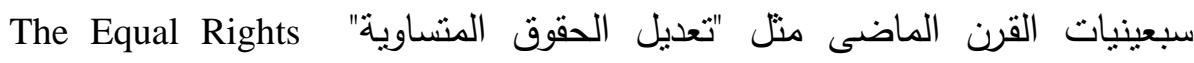
Amendment

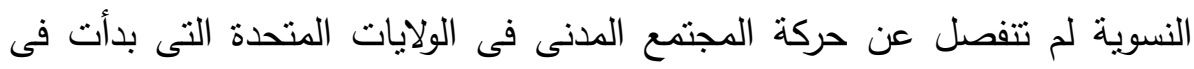

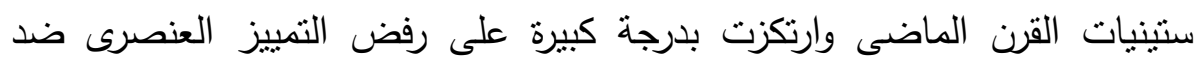

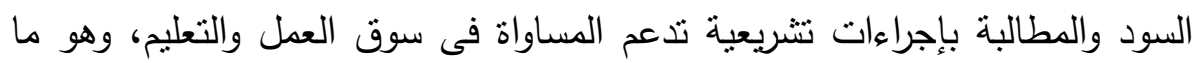

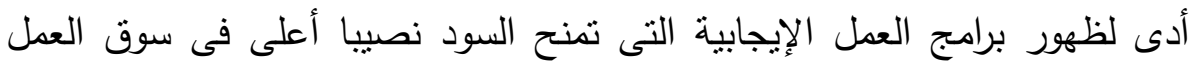

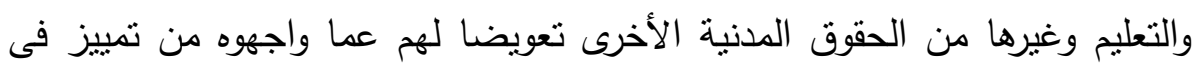

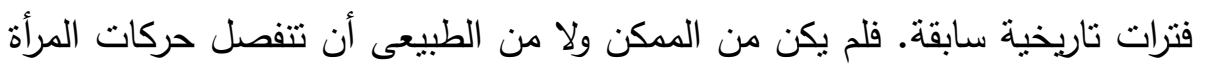
التى ظهرت فى سبعينيات القرن الماضى عن السياق القائم على نبذ التمييز العنصرى ضد السود والاستفادة من توجهاته بشكل عام. لقد مثلت حركة السود مهادا

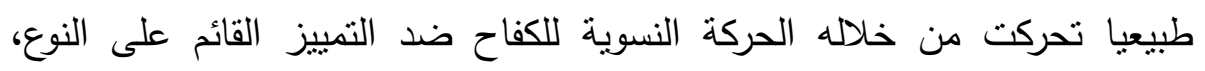
ودعما معنويا لهاب(7). وعلى الرغم من النجاحات التى حقتتها النظرية اللييرالية فى دعم المرأة على

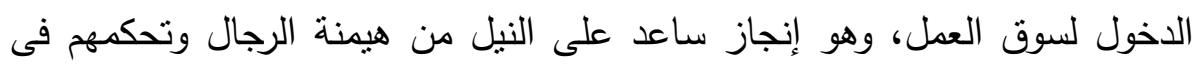


فرص العمل المتاحة، فإنها كانت أقل نجاحا فى القضاء على أنثكال التمييز الأخرى

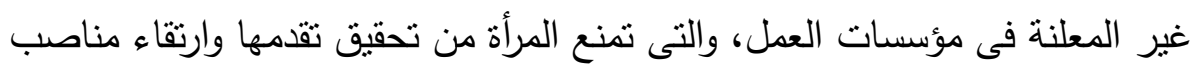

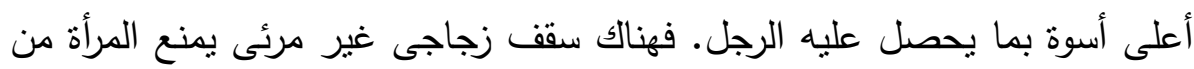
التزقى والحصول على مناصب أعلى فى مؤسسات العمل التى تلتحق بها، وهو

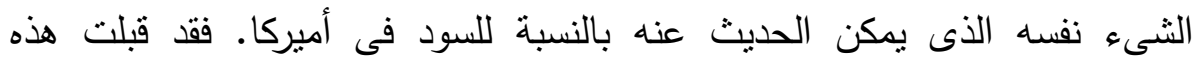

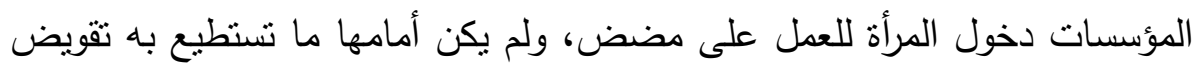

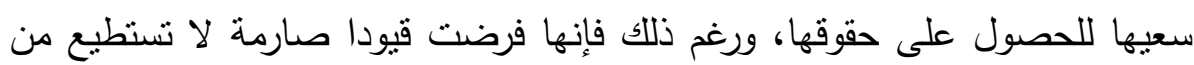

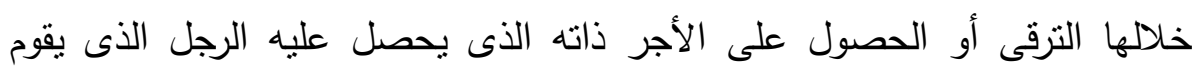

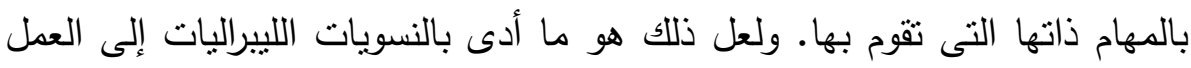

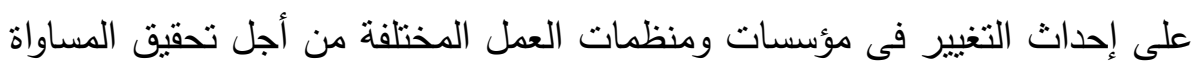

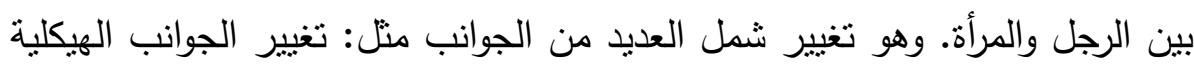

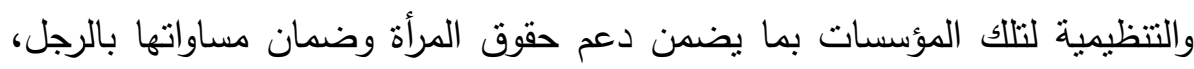
واستحداث التنشريعات المواكبة لهذه الهيكلة والتنظيم بما يضمن صيانة حقوق المرأة والمكتسبات المؤسساتية الخاصة بها. وهذا لا يعنى أن ما حققته النظرية الليبرالية لم يكن شيئًا مهمًا؛ العكس هو العاه الصحيح، فقد كانت أول خطوة وأهم محاولة نحو تحقيق المساواة بين الجنسين. والأهمية النى يمكن عزوها لهذه النظرية لا تكمن فقط فيما حققته بقدر ما تكمن أيضا

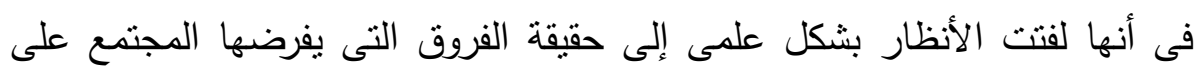

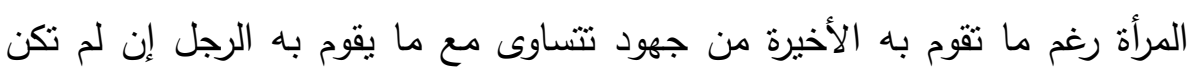

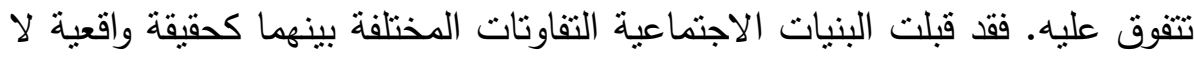

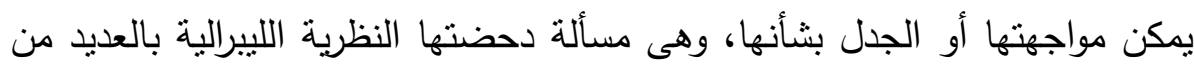
الأعمال الفكرية والكثير من الجهود السياسية. ووفقا لكامبل وواسكو Cambell and Wasco فإن النسوية الليبرالية قد دافعت

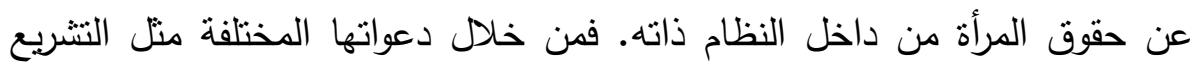


للمساواة بين الجنسين، والمساواة فى الأجور وفرص العمل المتاحة، سعت إلى تغيير البنية القانونية للمجتمع مع البقاء عليه والحرص على مؤسساته؛ فالنسوية الليبرالية لا تتحدى بشكل مباشر الهياكل المؤسسة للأنظمة الاقتصادية والسياسية والتشربعية القائمة بما يساعد على تغييرها وإحلالها. فلم تكن النظرية راديكالية فى الذهاب بعيدا نحو تقويض الأسس التى يقوم عليها المجتمع الرأسمالى وإحلال أطر سياسية واقتصادية محله. فالهدف النهائى للنظرية تمثل فى تحسين ظروف المرأة وتحقيق تكاملها ضمن بنى المجتمع المختلفة دون التمرد عليها أو الخروج على أسسها، وهو

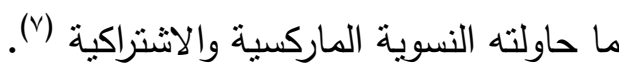

Marxist and Socialist Feminism النسوية الماركسية والاشتراكية تتطلق النسوية الماركسية والاشتراكية من فلسفة كارل ماركس للوجود والحياة

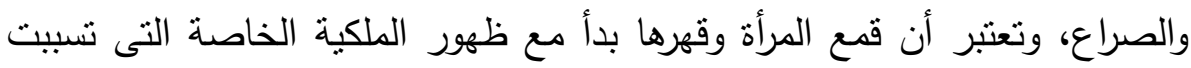
فى قيام علاقات غير منساوية وغير منوازنة تصنف الأدوار والأنشطة وفقا لمعايير جنسية، فالماركسية تشكل الوعاء العام الذى انطلق منه هذا التيار وأسس وفقا له الكثثر من الافتراضات القائمة على التمبيز ضد المرأة. وبينما نركز النظرية النسوية الليبرالية بشكل رئيس على المساواة فى الحقوق بين الرجال والنساء بشكل عام، فإن النظرية النسوية الماركسية والاشتراكية نركز على أنثكال الظلم التى تواجها النساء بالنظر لأمرين هامين: أولهما اعتمادهن على الرجال، وثانيهما استغلالهن كمصدر رخيص ضمن قوة العمل الرأسمالية (^) . وتتاقث النظرية الظلم الذى تعانى منه المرأة بسبب تعرضها لأثكال عديدة من الاستغلال سواء فى بيت أسرتها كابنة فى مرحلة ما قبل الزواج أو فيما بعد فى بيت زوجها، ومن خلال حصولها على وظائف متدنية فى سوق العمل لا توفر لها سوى دخلا متدنيا مثلاها فى ذلك مثل العديد من الرجال الفقراء الذى لا يحصلون على دخل

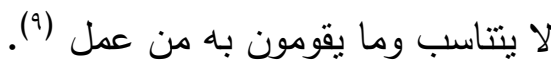


وعلى النقيض من النسوية الليبرالية فإن النسوية الماركسية والاثتراكية تحاول

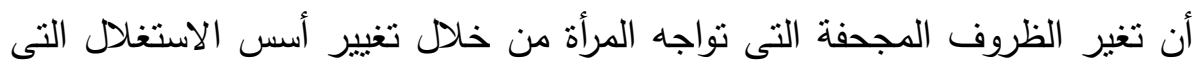

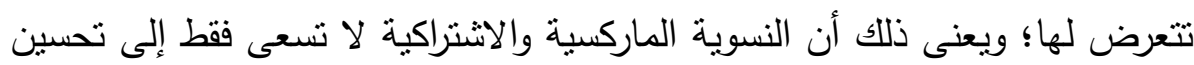

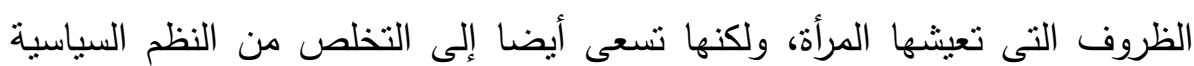
والاقتصادية والاجتماعبة التى تكرس أسباب استغلالها؛ والتخلص من النظام

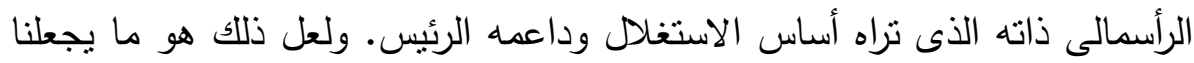

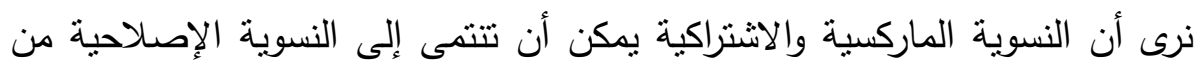

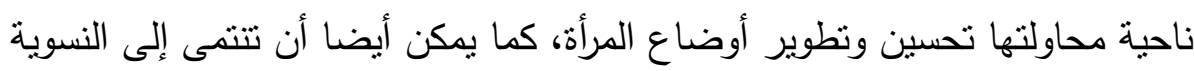

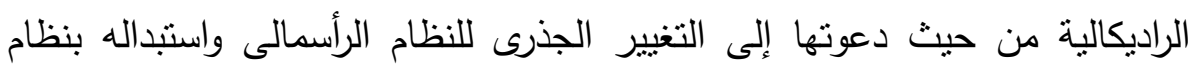

$$
\text { انشتراكى آخر يرتكز على العدل والمساواة. }
$$

وتؤكد النسوية الماركسية والاشتراكية على الارتباط بين النوع والطبقة، كما تركز على التمايزات الاجتماعية بين الرجال والنساء. وكما هو معروف فإن الطبقة

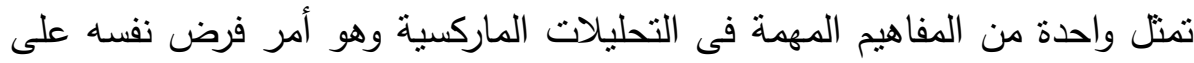

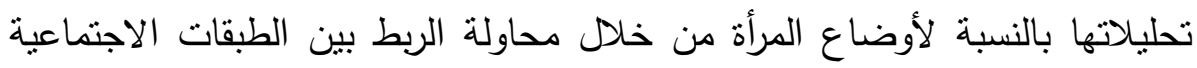
وبين التفاوتات المختلفة القائمة على التمييز وفقا للنوع. من هنا فإن النسوية

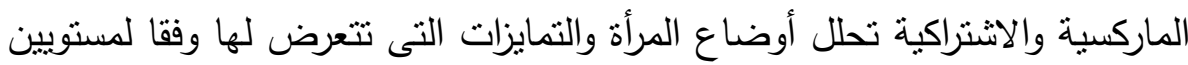

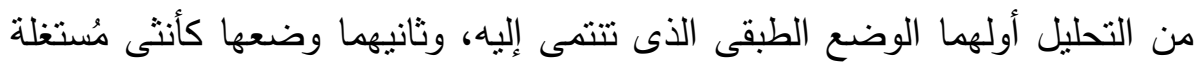

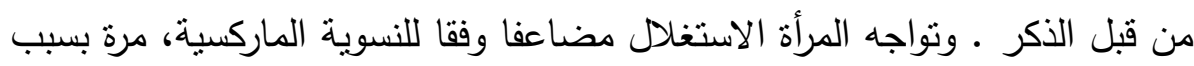
انتمائها الطبقى، ومرة أخرى بسبب انتمائها الجنسى. ومن الجوانب المهمة هنا توسيع الروئة بالنظر لعملية الاستغلال المجتمعى المئي

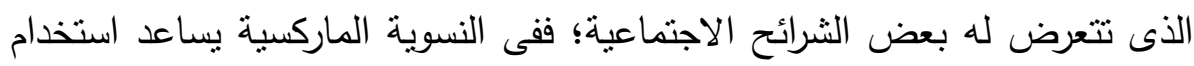

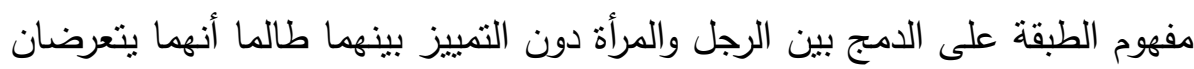

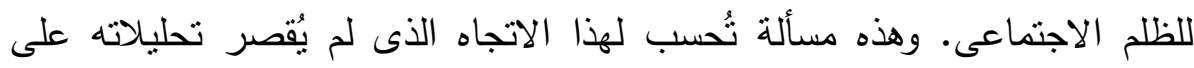


ظروف الاستغلال الذى تتعرض لها المرأة لكنه ضم إليها أى فئات أخرى تتعرض

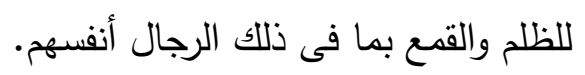

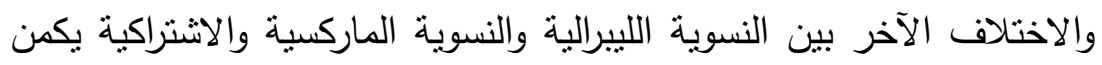

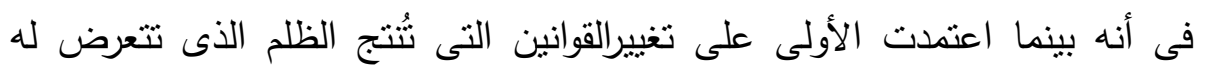

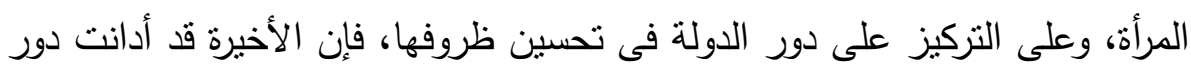

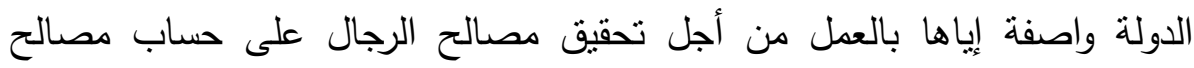

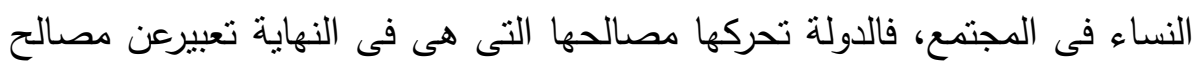

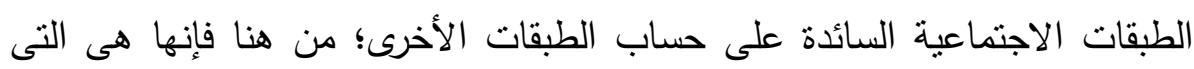

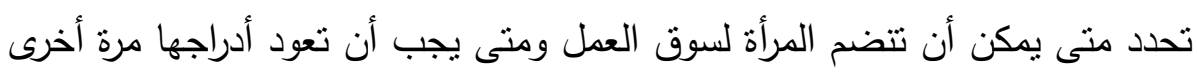

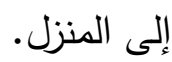

لقد أكتت النسوية الماركسية الظلم الذى تتعرض له الهرأة وعزت ذلك إلى الى الكي

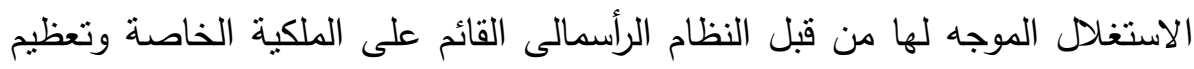

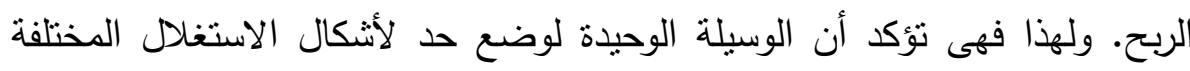

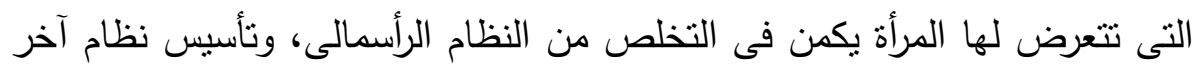

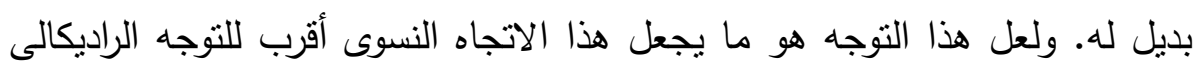
رغم طابعه الإصلاحى الواضح.

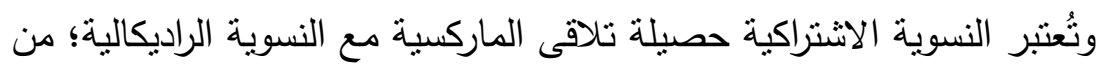

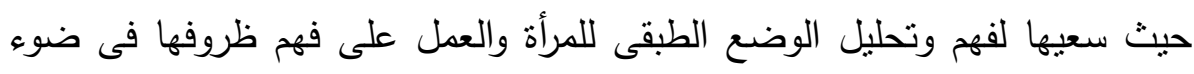
الاقتصاد السياسى للعمل المنزلى والعلاقات الأبوية (الباترياركية) الرأسمالية. فإذاذا

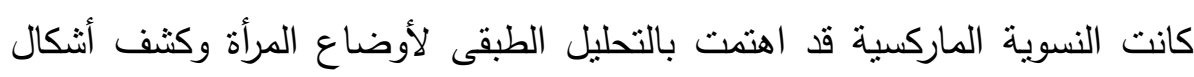

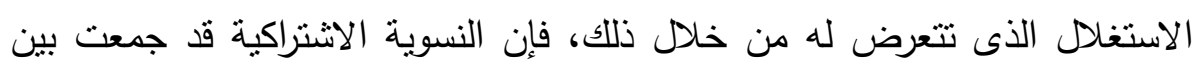

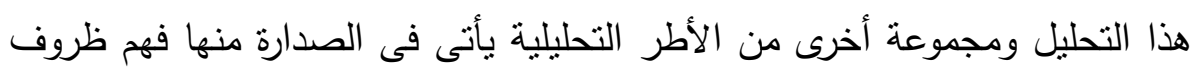

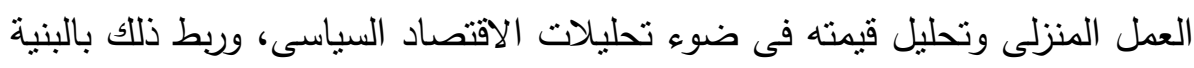


الأبوية المتسلطة الداعمة لهيمنة الذكور على الإناث ضمن الإطار الاستخلالى الأوسع للنظام الرأسمالى. - النه

ووفقا للتحليلات النسوية الماركسية والاشتراكية فإن الاستغله الذى تتعرض له المرأة فى البيت وسوق العمل هو المصدر الرئيس للتفاوتات القائمة على النوع. وارتباطا بذلك فإن هنالك مؤسستين منوازيتين تعملان معا من أجل تشكيل حياة الرجال والنساء على السواء أولهما تتمنل فى الاقتصاد حيث الرأسمالية، وثانيتهما تتمنل فى مونى

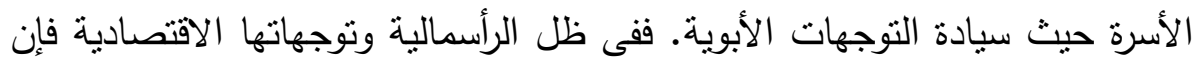
البنى الأبوية تجدلها وضعية مهمة تساعدها على التجذر واستمرارية بنية الاستغلال التى تتعرض لها المرأة؛ فالعلاقة بين النظام الرأسمالى والبنية الأبوية علاقة تعاضدية يساهم من خلالها كل طرف فى تدعيم الآخر ومساندته (·'). ومن خلال الجمع بين البنية الأبوية والبنية الرأسمالية، وفقا للنسوية الماركسية والاشتراكية، فإن المرأة تعانى من استغلال مضاعف؛ أولهما ذو علاقة بوضعيتها كزوجة وثانيهما ذو علاقة بموقعها فى سوق العمل الرأسمالى. بالنسبة لوضعيتها

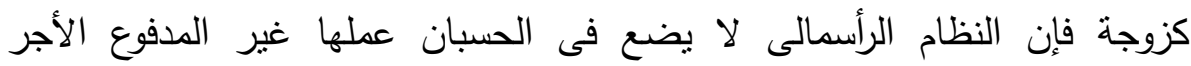
Unwaged Labor القيام فى أحيان كثيرة بأعمال منزلية تدر دخلا للأسرة، ناهيك عن دورها فى الحمل

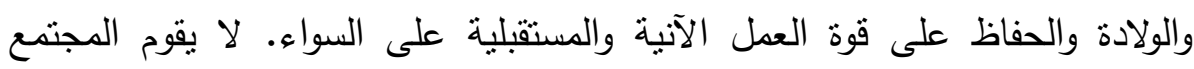
الرأسمالى بحساب قيمة ما ثقوم به المرأة من عمل منزلى؛ فهو عمل رغم أهميته المطلقة للمشروع الرأسمالى مُهمل من جانبه لا يتم الاعتداد به أو حسابه ضمن أرباح

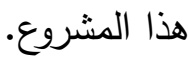
إن الطربقة التى يتعامل بها النظام الرأسمالى من ناحية وبنية الأسرة الأبوبة

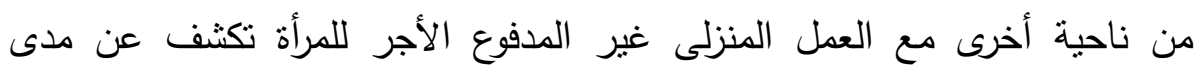
الاستغلال والقهر الذى تتعرض له المرأة ضمن هذا النظام والكيفية التى يتم من خلالها التعامل مع قوة عملها من فترة لأخرى حسب احتباجات النظام ومصالحه|('). 
ففى ضوء مصالح النظام الرأسمالى يمكن دعوة المرأة للاخول لسوق العمل وتتجيعها

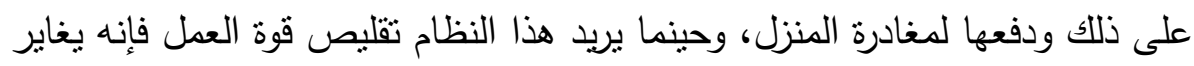

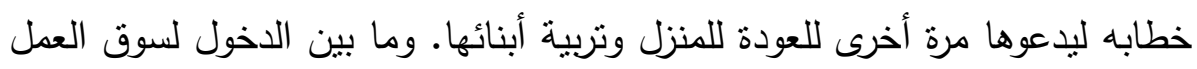

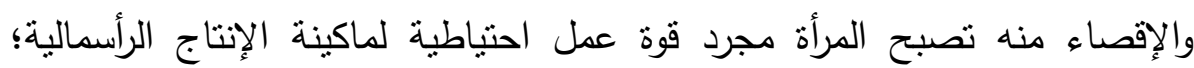

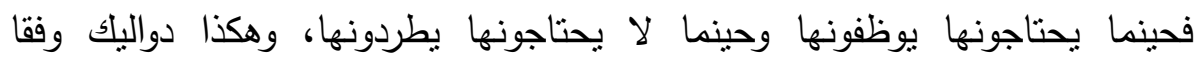
لمصالح النظام الرأسمالى والقائمين عليه. ووفقا لكل من Shelton and Agger فإن التفاوتات القائمة على النوع التى النى نواجهها المرأة فى سوق العمل ترتبط عمليا وأيديولوجيا بدورها فى العمل المنزلى غير لفي

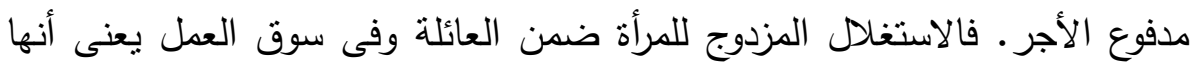

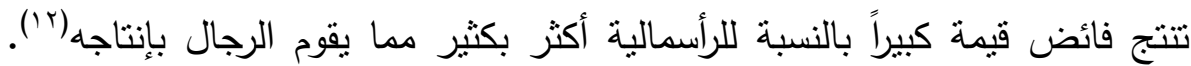

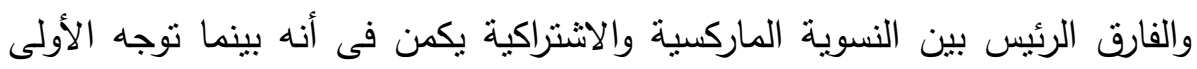

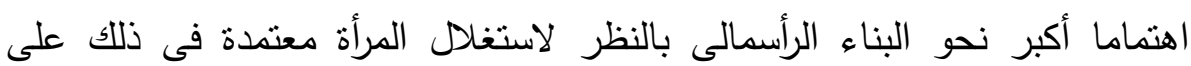
التفاوت الطبقى بين البروليتاريا والبرجوازية أساسا، فإن الثانية تركز على دور البنية الأبوية التى تسبق النظام الرأسمالى نفسه فى تدعيم وتأبيد قمع المرأة واستغلالها.

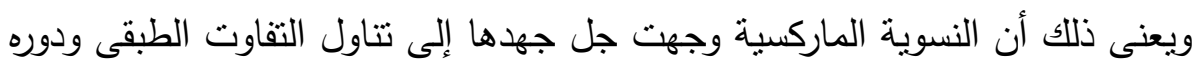

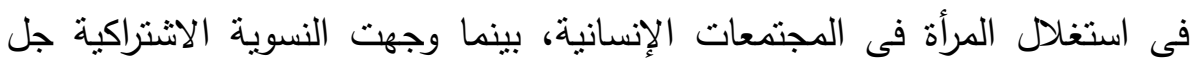
جهدها إلى دور البنية الأبوية التى رأتها الأقدم فى المجتمعات الإنسانية عبر التاريخ

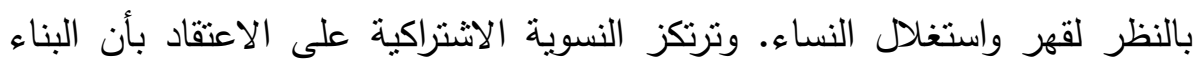

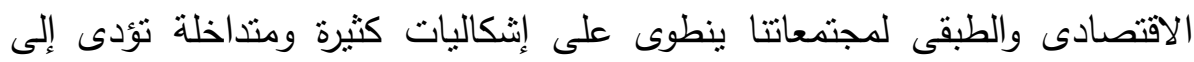

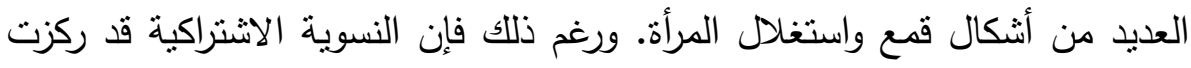
تاريخيا وبسبب من ارتباطاتها الأيديولوجية بالماركسية على النزعة الطبقية

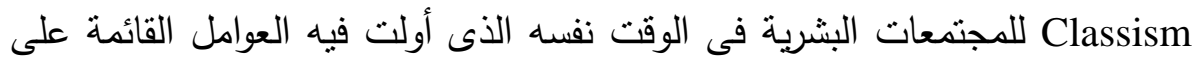
العرقية والجنسية Racism and Sexism اهتماما أقل (rا') . 
ومن خلال توسيع نطاق التحليل الماركسى ليشمل العمل غير مدفوع الأجر

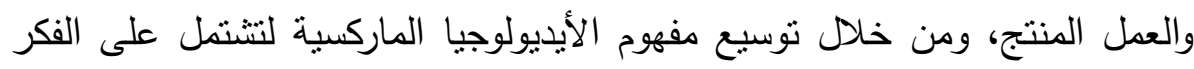

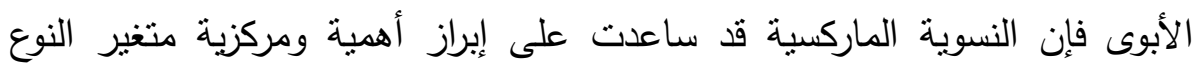

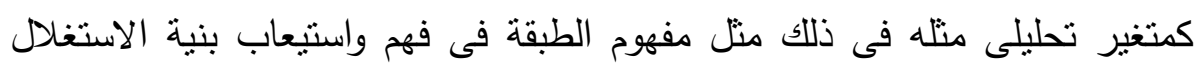

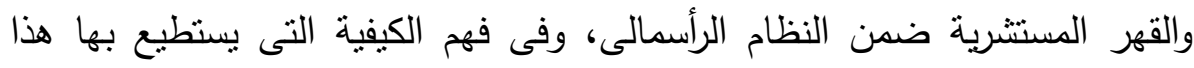

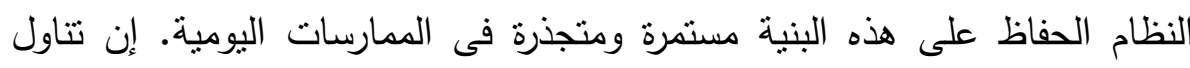
النسوية الماركسية لمتغير النوع ووضعه فى الاعتبار قد عمق بلا شك التفسيرات الماركسية المستندة بالأساس إلى التحليل الطبقى، وساعد بدرجة كبيرة على إعادة فهم

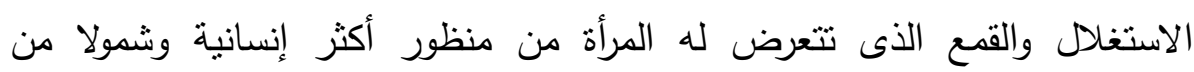
المنظور الطبقى الجامد الغافل عن متغير النوع ووجود المرأة.

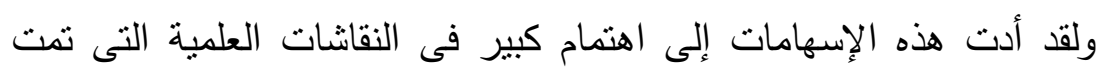

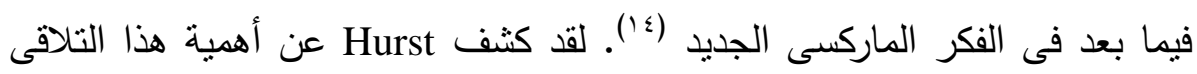

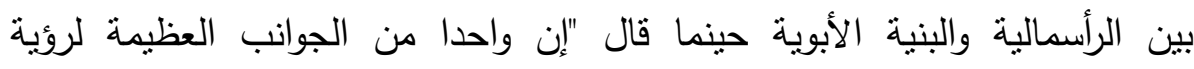

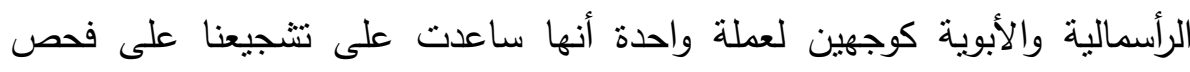
الارتباط القائم بين الطبقة والجنس فى أية محاولة تسعى لفهم الأدوار النسبية للارجال

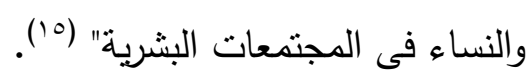

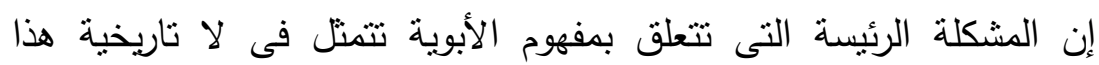

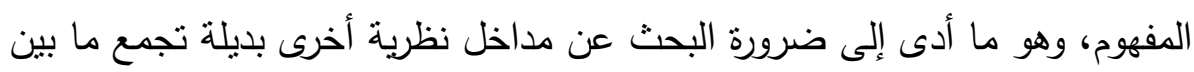

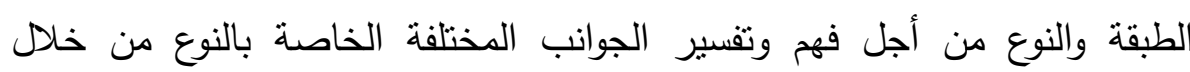

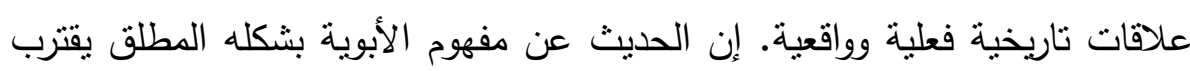

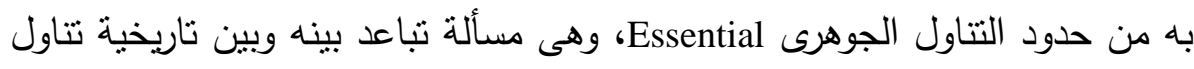

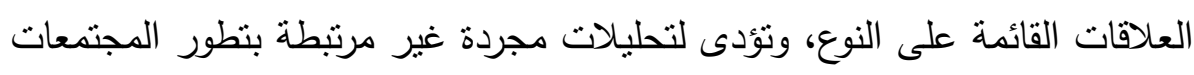
البشرية. بالإضافة إلى ذلك فإن الأبوية، وكما قال

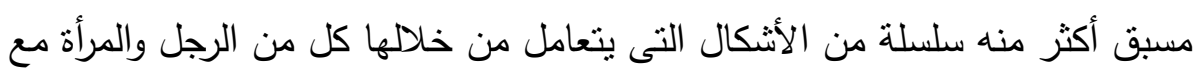


بعضهما البعض(17). والمقصود هنا أن تصور الأبوية كبناء نسقى محدد سلفا يُققدها تناولها وتفسيرها فى ضوء العلاقات الاجتماعية السائدة بين الرجل والمرأة وإمكانية الهنية الوصول إلى نسق تحليلى يعكس هذه العلاقات بدرجة كبيرة من الموضوعية والصدق. ورغم ذللك فإن هناك الكثرين الذين فسروا الظلم الذى تتعرض له المرأة من خلال النظام الرأسمالى فى ضوء العلاقات التى يتم بناؤها وتثكيلها Structured بين

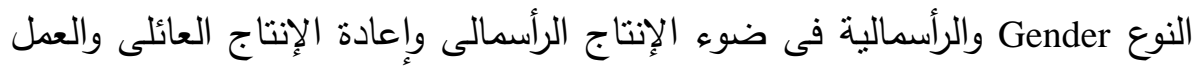

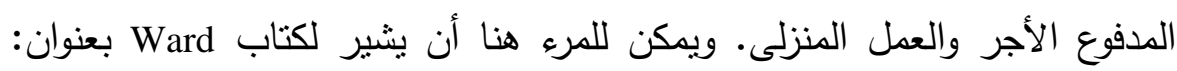

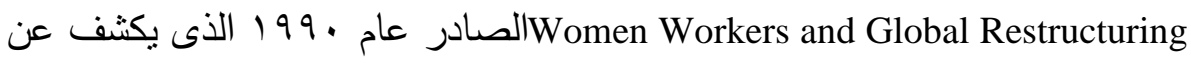
تأثثرات دول المركز الرأسمالى عبر تغلغلها فى الدول الهامثية، التى تثنتمل على

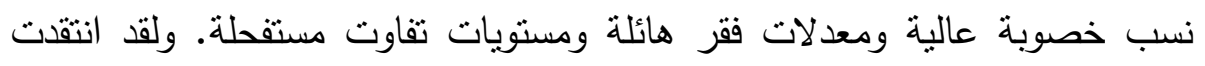
نظرية النظام العالمى بسبب تركيزها فقط على الأدوار النى تلعبها النساء فى النى

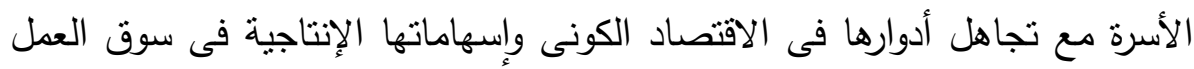

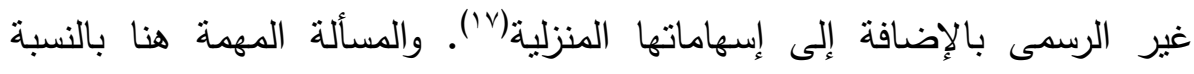

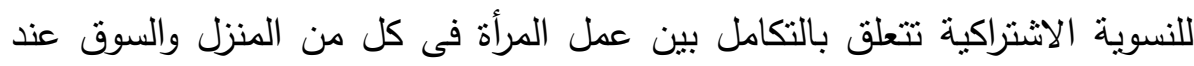

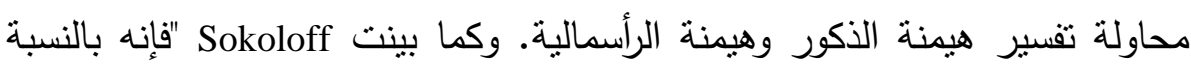

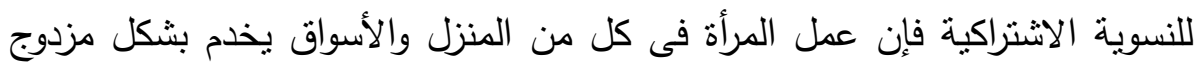

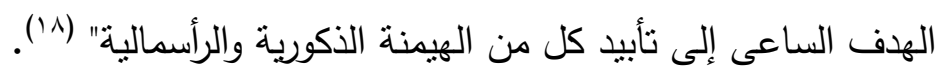

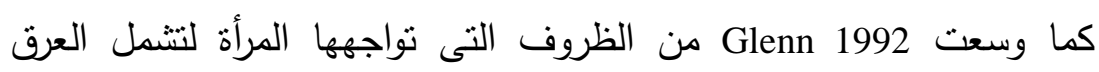

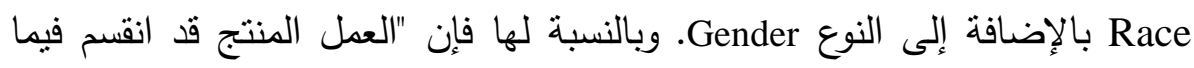

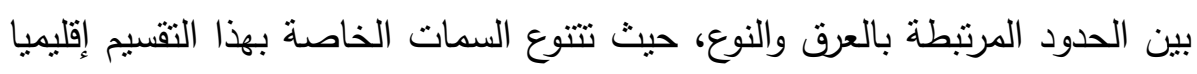

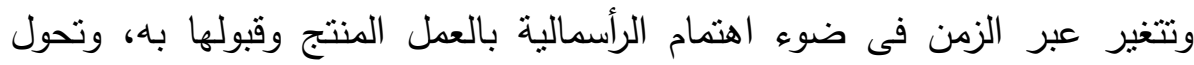

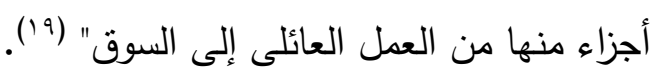


وعلى الرغم من قيام لوربر Lorber بتصنيف النسوية الماركسية والاشتراكية بوصفهما نظريات إصلاحية، فإننا نرى بأنها يجب أن يُصنفا ضمن النظريات

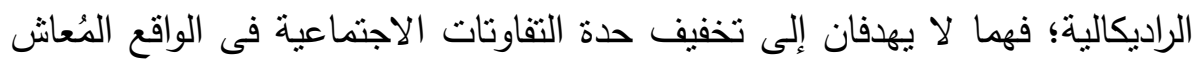
بقدر ما يهدفان إلى تغيير هذا الواقع ذاته بشكل جذرى. لكن رغم ذلك، وبسبب من تركيزهما على المرأة بشكل عام فقد وُجهت لهما العديد من الانتقادات من النساء الملونين Colored Women، وهو مصطلح يشتمل على كافة النساء من غير ذوى البشرة البيضاء مثل الأمبركيين من أصول إفريقية أو غيرهن من الآسيوبين واللاتين...إخخ، بسبب تجاهلهن وعدم إيلاء وضعيتهن العرقية والإثثية أية خصوصيات تحليلية ضمن هذه النظرية، وهو أمر اهتمت به على نحو رئيس النسوية المعنية بالتعددية العرقية Multiracial Feminism كما سوف نوضح لاحقا.

\section{ثانيا: النظريات النسوية المقاوهة Gender Resistance Feminism}

تؤكد النسوية المقاومة على تأثثر البنية الأبوية على العلاقة بين الرجل والمرأة، وكما قالت لوربر Lorber فإن "هذه البنية الأبوية يمكن العثور عليها فى أى مكان يحدث

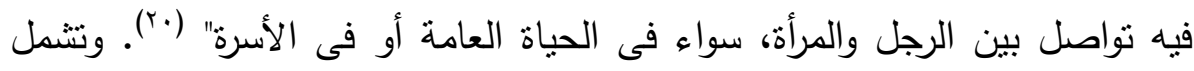
هذه المجموعة من النظريات النسوية الراديكالية Radical Feminism، والنسوية السحاقية Lesbian Feminism، ونسوية التحليل النفسى Psychoanalytic Feminism؛ وجهة النظرالنسوية Standpoint Feminism.وتكشف نظريات النسوية المقاومة أن قهر المرأة والحط من وضعيتها يمثل جانبا مهمًا من الأيديولوجيات والقيم الخاصة بالحضارة الغربية. وتمثل هذه الأيديولوجيات والقيم قاسما مشتركا فى العديد من مجالات الحياة اليومية، فى الدين، والإعلام الجماهيرى، والرياضة، والمنتجات التقافية. وتعطى النسوية المقاومة اهتماما أكبر للاستخلال الجنسى والعنف المرتبط به، وبشكل خاص الاغتصاب والمواد الإباحية Pornography بوصفها وسيلة من وسائل السيطرة على النساء. وفيما يلى سوف أتتاول بالتحليل اتجاهين نظريين من النسوية المقاومة وهما النسوية الراديكالية ونسوية وجهة النظر . 


\section{ا- النسوبة الرادركالية Radical Feminism}

تُوصف هذه النظرية بالراديكالية لأنها ترى قهر المرأة بوصفه واحدا من أهم أشكال القهر المجتعى التى لا تقف فقط عند المرأة لكنها تثقاطع مع الحدود العرقية والثقافية والطبقات الاقتصادية. من هنا فان هذه النظرية نوسع من تتاولها للقهر الذى تتعرض له المرأة ضمن كافة المواضعات الاجتماعية التى تشمل العرق واللون والثقافة والطبقة. ويتمثل الهدف الرئيس لهذه النظرية فى تغيير المجتمع الذى توجد فيه المرأة

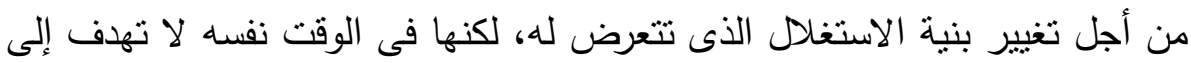
تثويره بشكل كلى وكامل.

وتكثف النسوية الراديكالية عن الاستغلال الجنسى الذى تتعرض لله المرأة

والذى يؤيد الهيمنة الأبوية للرجال على النساء. ووفقا للوربر Lorber فإن هذا المدخل يوسع مفهوم الأبوية من خلال تعريفه بوصفه نظاما عالميا يستتد إلى خضوع المرأة

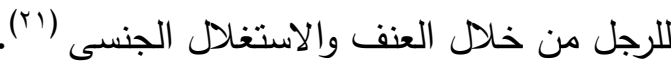
ويشير كوكوبيلى ولاكى Kokopeli and Lakey إلى كل من الجنسانية الذكورية والأبوية بوصفهما نظامين متكاملين يدعمان ويكرسان استخلال النساء فى المجتمعات البشرية. فالجنسانية الذكورية تدعم الممارسات الجنسية بين الذكور والنساء Heterosexuality بشكل رئيس على حساب المنلية الجنسية Homosexuality كما أن الأبوية تمثل بنية عريضة ومُمَأسسة من هيمنة الرجال على النساء عبر الفرص والمكافآت وأنشكال العقاب غير المتساوية، ومن خلال استدماج وقبول التوقعات بعدم التساوى المستتدة إلى اختلافات الدور الجنسية (rr). وتنتمل البنية الباترياركية على نطاق عريض من الهيمنة يسمح للرجال بأن

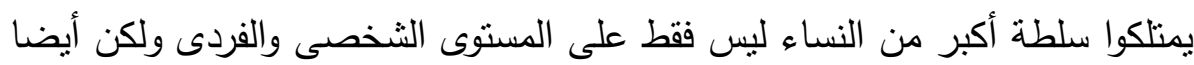
على المستوى السياسى. ويكمن الهدف الرئيس للنسوية الراديكالية فى الاشتباك فى صراع القوة ضد الرجال والمؤسسات التى تم تشييدها من قبلهم. وتختلف النسوية الاشتراكية عن النسوية الراديكالية من ناحية تحديد سبب القهر الذى تتعرض له المرأة 
فى المجتمعات الإنسانية؛ "ففى تضاد مع النسوبين الاتشتراكيين، الذين يحددون الرأسمالية بوصفها المصدر الرئيس للقهر فإن النسويين الراديكاليين يحددون النزعة

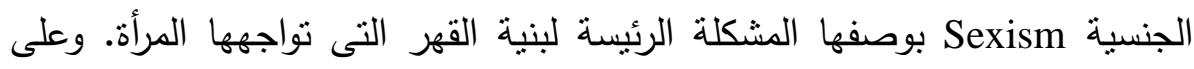
خلاف النسويين الليبراليين، الذين قبلوا بالبنية الاجتماعية العامة للمجتمع بينما رفضوا قواعده الخاصة بإعادة نوزيع الدخل، فإن النسوبين الراديكاليين قد رأوا بأن النظام بلهابن الاجتماعى ككل يجب إعادة فحصه وإعادة تحديده من جديد" (rr). وتكمن مشكلة هذا المدخل، الذى هيمن بشكل رئيس على النظريات النسوية فى ستنيات وسبعينيات القرن الماضى، أنه ركز بشكل أساسى على دراسة الفوراق لئن بين النساء والرجال ككيانين متضادين ومختلفين بشكل كلى بديلا عن دراسة الفوراق التى يواجهانها مجتمعيا. فهناك فوارق نواجه الرجال والنساء مقارنة بغيرهم من الرجال

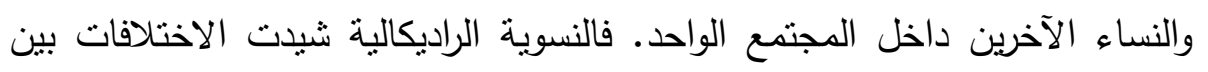
الرجل والمرأة بناء على الاختلافات البيولوجية فيما بينهما وعلى النظام الأبوى. ولقد أدى تبنى مفهوم الأبوية إلى منظور مزدوج يرنكز على قبول مسبق يستتد إلى إنى

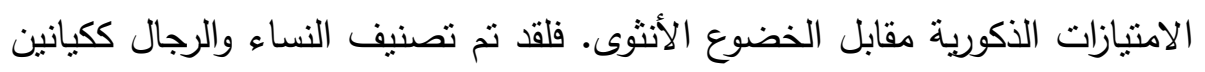
متعارضين، وذللك من خلال التعامل معهما بوصفهما جماعتين متجانستين من ناحية الخبرات والسمات المشتركة. فالتتاول الذى يستتد إلى الجوهر Essentialism والذى منى يتعامل مع الظواهر المدروسة بدون إحاطة بالتغيرات المجتمعية الوجودية المحيطة

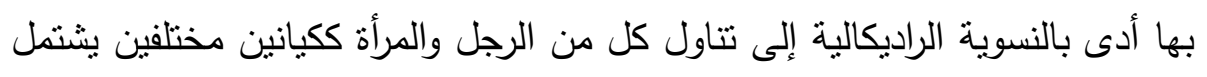

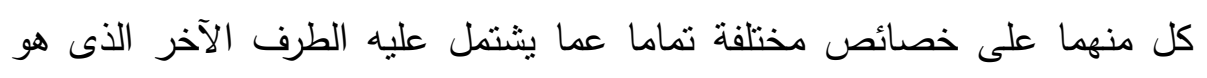
النقيض وفقا لطبيعة هذا التناول. ومن هذا المنطلق فإن الخلاصة تكمن فى أن سيطرة الذكور وقهر النساء هو ما بنتج الصراع الحادث بين الجنسين (عَr).

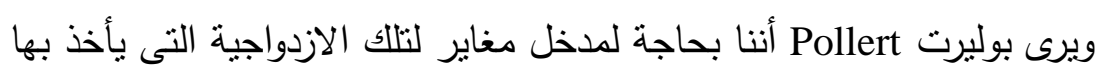
المدخل النسوى الراديكالى والتى تجمع بين الرأسمالية والأبوية، حيث يقترح مدخلا يتجاوز ذلك إلى مدخل آخر يفهم النوع بوصفه مرتبطا بالعلاقات الاجتماعية كافة 
وغير منفصل عنها. ويأتى اقتراح بوليرت منوافقا مع النقد الذى توجها شيرى موريدج Cherrie Morage

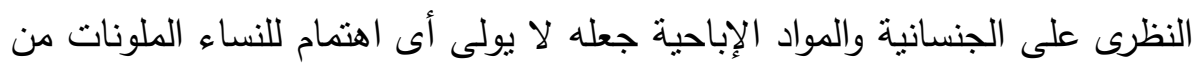
ناحية ولعوالم النساء الفقيرات اللاتى ينتمين للعالم الثالث من ناحية أخرى (10).

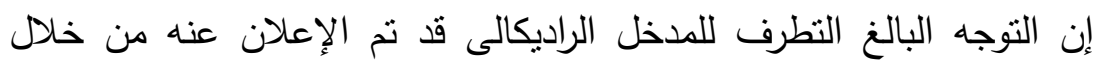

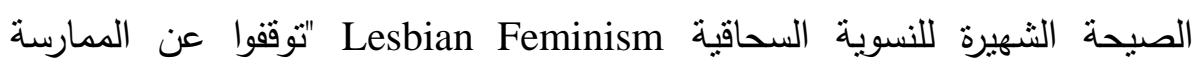
الجنسية مع عدونا، وتحولوا إلى النساء بحثا عن الثغف الجنسى والصدية الصحبة الفكرية

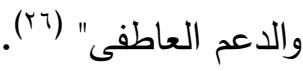

\section{Y-وجهة النظر النسوية Standpoint Feminism}

ولكى يتم تجنب هذا التقسيم الصارم بين الرجال والنساء تلاقت النظريات النسوية

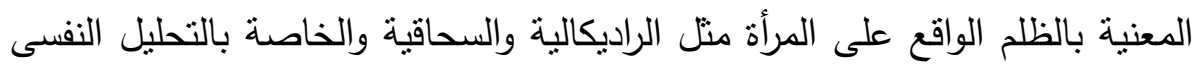

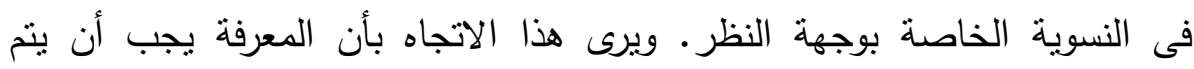

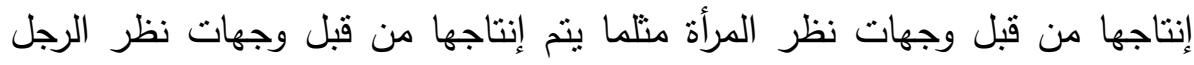

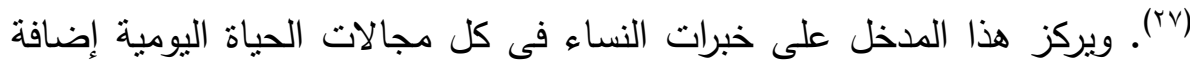

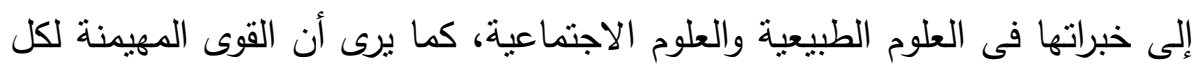

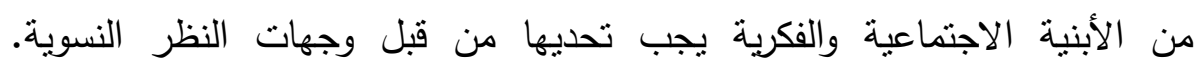

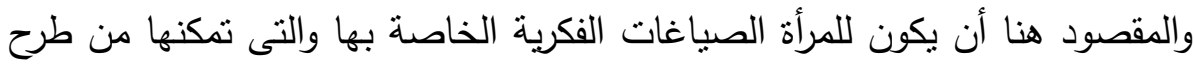

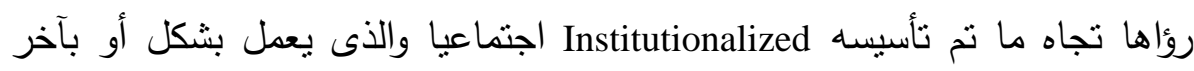
على تجذر البنى التى تؤدى لاستغلالها والهيمنة عليها. فالقوى المهيمنة للأبنية

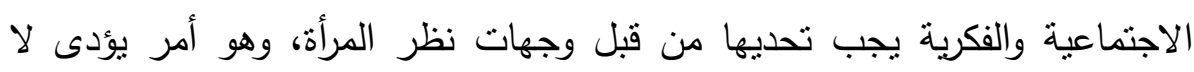

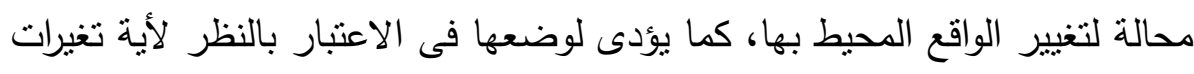

$$
\text { مجتمعية محتملة ومتوقعة. }
$$

لقد أشارت شافيتز Chavetz على سبيل المثال إلى فنشل علم الاجتماع بشكل

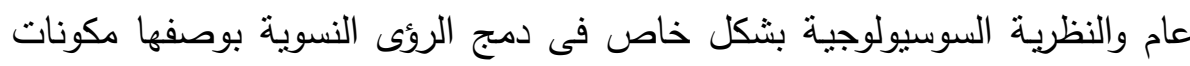


أساسية من أعمالهما. كما أنها أثنارت إلى المُنظرين المعاصرين الشهورين جدا الذين أغفلوا النظرية النسوية بشكل عام مثل جيمس كولمان James Coleman، جيفرى الكسندر Jeffrey Alexander، بيتر بيرجير Peter Berger، وأنتونى جيدنز Anthony Giddens

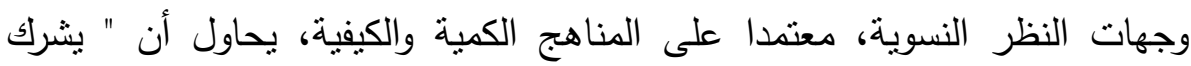
النساء المشتركات فى البحوث فى التعرف منهن على الكيفية التى تتشكل خبراتهن منها فى العالم الاجتماعى منل أنواعهن وأعراقهن والطبقات الاجتماعية اللاتى ينتمين إليها وتوجهاتهن الجنسية" (ra). ويتحدى هذا الدذخل ما يبدو أنه حقائق ثابتة ومقبولة، وبشكل خاص الافتراضات الكونية عن النساء، والتى تؤطر عالمها وتحدد لها سلوكياتها. وهذا التحدى سوف بساعد فى نقد الغرب أو وفقا لسمير أمين سوف بساعد فى نقد "الرؤى

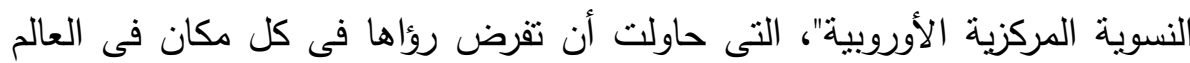
بغض النظر عن الاختلافات الاجتماعية والسياسية والاقتصادية (·.).

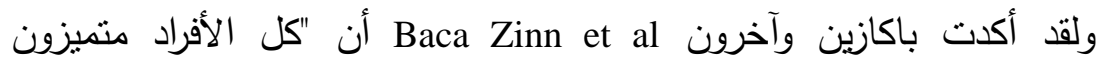

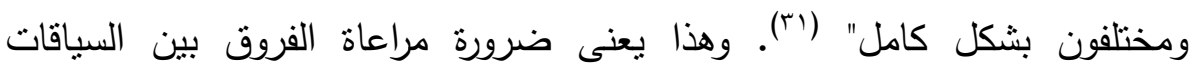
الاجتماعية المختلفة، والفروق بين وضعية المرأة وظروفها فى كل بلد على حدة، وهو أمر يساعد بشكل كبير على تفهم المرأة فى ضوء الأوضاع التى تتنمى إليها مما

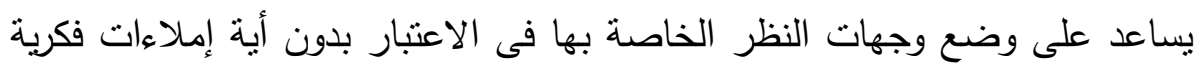

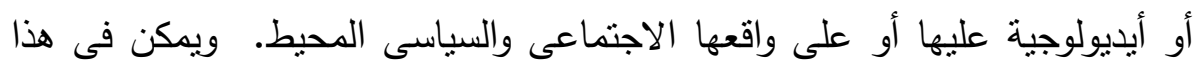

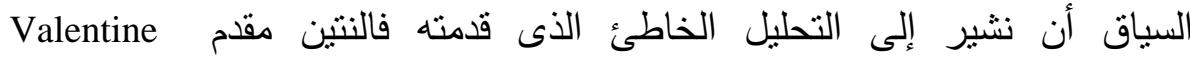

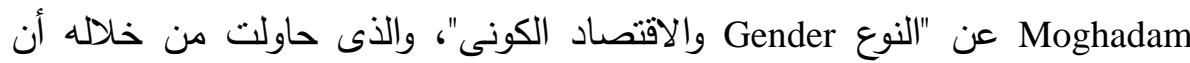

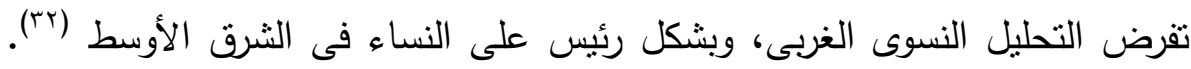

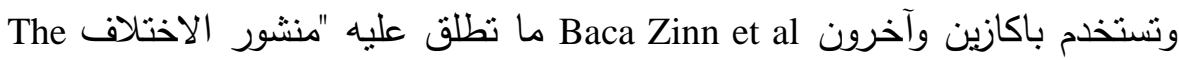
"Prism of Difference 
علاقات النوع المعاصرة. ويساعد هذا المنظور على استيعاب الأنواع الدختلفة من

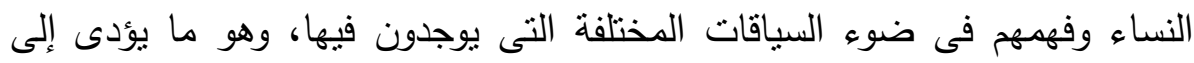

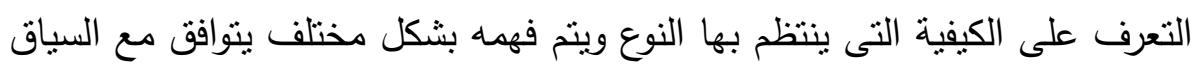

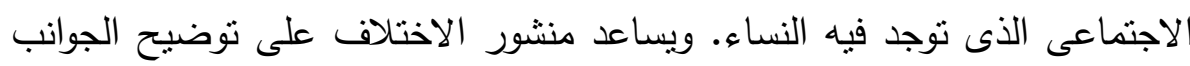

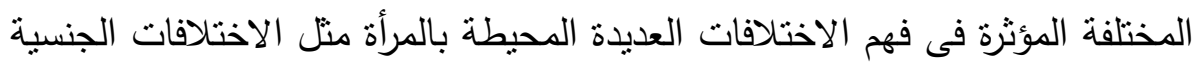

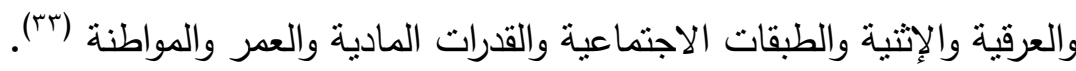

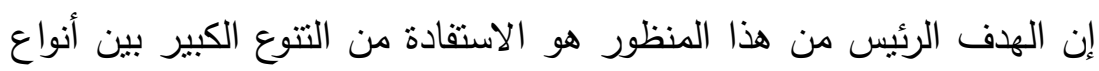

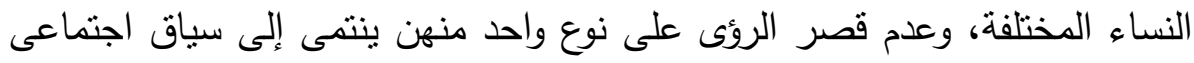

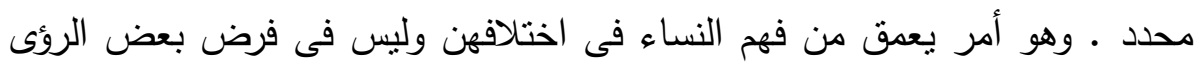

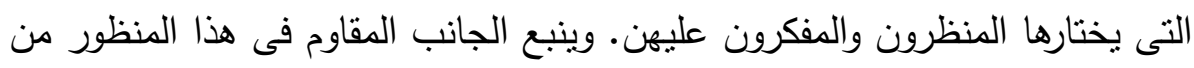
كونه برفض فرض توجه معين وواحد على النساء بمعزل عن التصورات الخاصة بهن

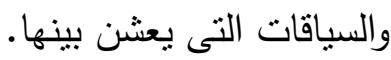

\section{Gender Rebellion Feminisms ثالثا: النظريات النسوية المتهمردة}

منذ أواخر ثمانينيات القرن الماضى، أصبحت النسوية المتمردة أكثر الثبارات النظرية النئية

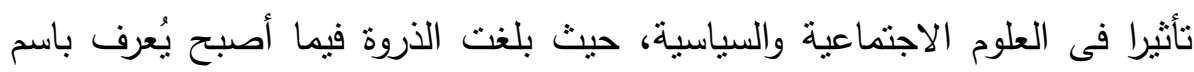

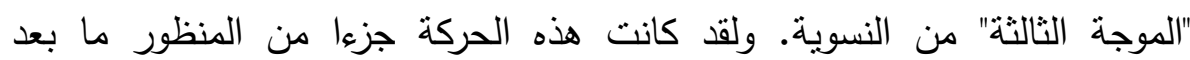
الحداثى الذى شكك فى الدقدمات الراسخة والمتعارف عليها للمجتمع والعلوم

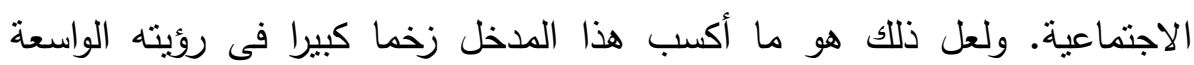

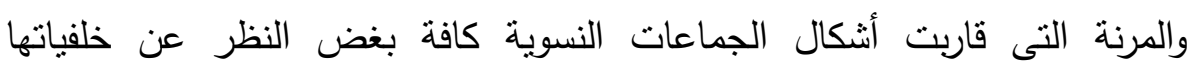

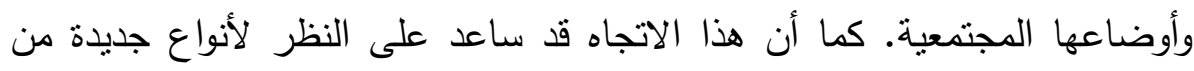
النساء اللاتى لم تتتاولهن الاتجاهات النظرية السابقة، وعلى رأسهن الفقراء والملونون الأناء

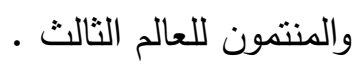

وتتنمل النسوية المتمردة على العديد من المداخل النظرية مثل النسوية المتعددة الأعراق، والنسوية النى تتعلق بالرجال، ونسوية ما بعد الحداثة، والنظرية 
التى تستتد على دراسة كل ما هو غريب للأطوار Queer Theory. وبسبب أهميتها وهيمنتها على العلوم الاجتماعية والتوجهات النسوية، فإننا سوف نناقش مدخلين نظريين منها هما النسوية متعددة الأعراق، والنسوية الغرائبية وما بعد الحداثية.

\section{Multiracial Feminism النسوية هتعددة الأعراق}

يُطلق على النسوية متعددة الأعراق أيضا اسم النسوية متعددة الإثثيات أو متعددة الثقافات، وهى تؤكد على أهمية الجمع بين النوع وغيره من العناصر الأخرى منل الأعراق والجماعات الإثتية والطبقات الاجتماعية من أجل فهم التفاوتات المرتبطة بالنوع (๕). ويؤكد هذا المدخل على أهمية التقاطع بين النوع والعرق والجماعة الإثنية والطبقة الاجتماعية بما بساعد على الفهم الثامل والكلى لوضعية المرأة فى لئ المجتمعات الإنسانية المختلفة. وهذا التحليل التقاطعى يؤكد على أنه فى غير مقدور أى شخص أن يركز بشكل رئيس على عنصر واحد من هذه العناصر ويتجاهل العناصر الأخرى فى الوقت نفسه. وهذا لا يعنى أن المرء يمكنه أن يضيف هذه

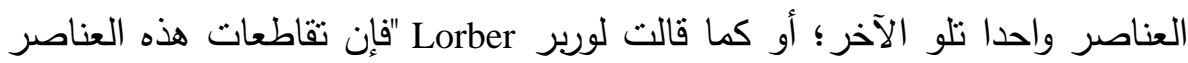
متآزرة معا، فجميعها تشيد معا موقعا اجتماعيا، وبعض هذه المواقع يتسم بدرجة أكبر من الاستبداد عن الأخرى بسبب كونها نتاجا لأنظمة متعددة من الهيمنة" (ro).

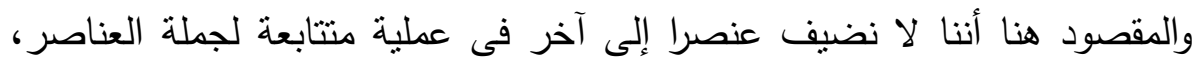
لكن ما يتم هو عملية بناء شاملة تترابط فيما بينها هذه العناصر وفقا لحجم تأثثراتها على وضعية المرأة؛ فقد يكون للوضع الطبقى تأثنير أكبر فى بعض المجتمعات على هلى

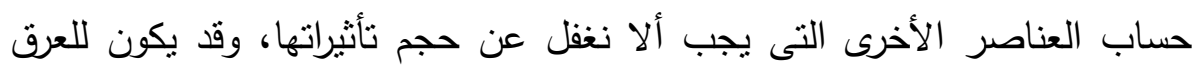
تأثنر أكبر فى وضعية اجتماعية أخرى ضمن مصفوفة العناصر الأخرى المساعدة على خلق هذه الوضعية... وهكذا. ويتبنى أندرسون وكولينز Anderson and ما يطلقان عليه اسم "مصفوفة الهيمنة" Collins أن الهيمنة فى المجتمع لا تتبع من عنصر وحيد بقدر ما تتبع من عناصر متعددة مثل العرق والطبقة وعلاقات النوع. ومن خلال التركيز على مصفوفة الهيمنة فإنهما 
يفصلان مدخلهما عما يطلقان عليها النموذج الإضافى Additive Model الخاص بدراسة التفاوتات الاجتماعية والذى يفتقد الارتباطات البنيوية الاجتماعية بين النوع الإعى والعرق والطبقة. وهذه الارتباطات هى ما يساعد على الفهم العميق لبنية القهر

والهيمنة التى تتعرض لها المرأة فى ضوء التركيبة الاجنماعية التى توجد فيها (بr). وفى ضوء ذلك فإن هذا المدخل يسعى إلى توضيح الفكرة القائلة بأن حالة

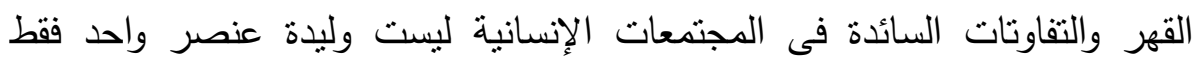
بقر ما أنها وليدة شبكة مترابطة من العناصر المختلفة. فعلى سبيل المثال، فإن العناصر التى تشمل النوع والعرق والجماعات الإثثية والطبقية تشكل فى الولايات المتحدة بنية تراتبية اجتماعية معقدة تساعد البيض من الرجال والنساء المنتمين إلى الطبقة العليا على قهر واستغلال الرجال والنساء المحرومين عرقيا وإنثيا ودينيا من المنتمين للطبقة الدنيا. وبالطبع ففى مجتمعات أخرى يمكن أن توجد عناصر حاكمة أخرى غير ما عليه الحال فى المجتمع الأميركي؛ فالوضع بين نساء العالم العربى على سبيل المثال يختلف بدرجة كبيرة، حيث تحكمه التصورات الدينية الخاطئة والبنية الثقافية الذكورية الحاكمة، إضافة إلى طبيعة التفاوتات المادية القائمة على استغلال السواد الأعظم من الثعوب لصالح شرائح اجتماعية محدودة. ووفقا لباكازين وديل فإن الأفكار الأساسية التى تتطوى عليها النسوية المتعددة

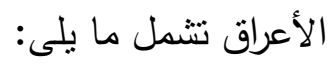

1- يتشكل النوع من خلال نطاق منسع من التفاوتات المترابطة. r- تمثل الطبقة والعرق والنوع والجنسانية مكونات البناء والتفاعل الاجتماعيين. r- تمثل السلطة حجر زاوية فى الاختلافات بين النساء. ع - يوجد تفاعل جدلى بين البناء الاجتماعى والقوة التى تحوز عليها المرأة. 0- يعتمد النوع على نطاق واسع جدا من المداخل النظرية والمنهجية الجديدة. 7- وأخيرا، فإن بنية النوع تتشكل من خلال خبرات الحياة الخاصة بالجماعات المتتوعة والمتغيرة بشكل مستمر من النساء (بحانه 
إضافة إلى الأفكار السابقة يمكن الإثارة إلى ما يسميه أندرسون وكولينز Anderson and Collins

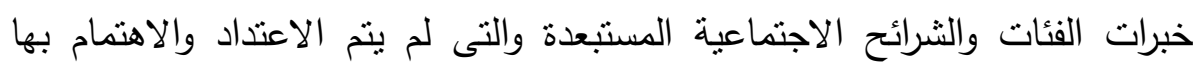

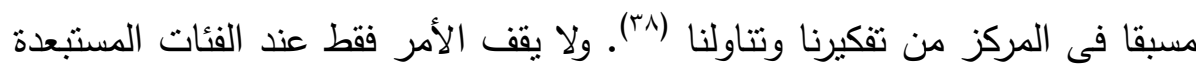

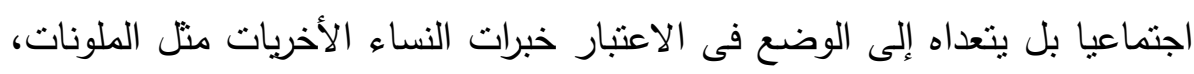

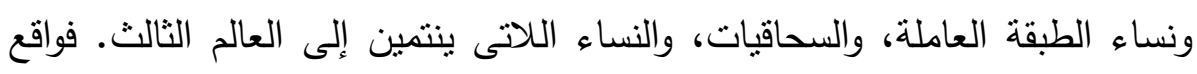

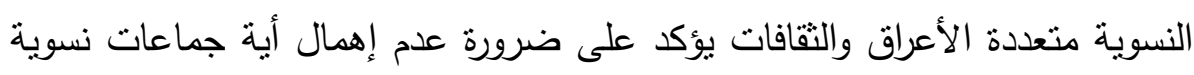

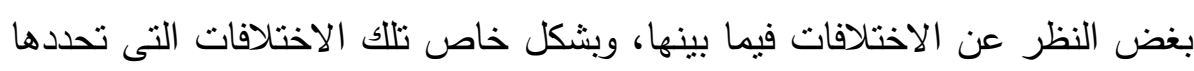

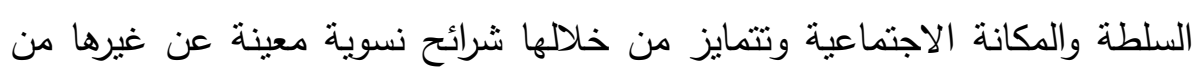

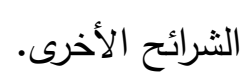

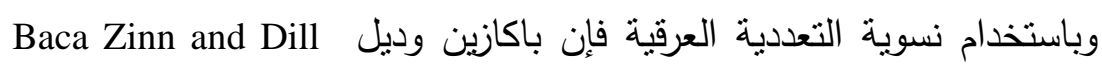
يتمثلان فى كتابهما الدحرر "النساء الملونات" Women of Color الخبرات الحياتية

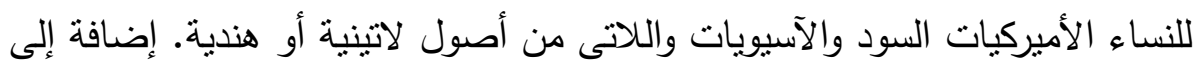

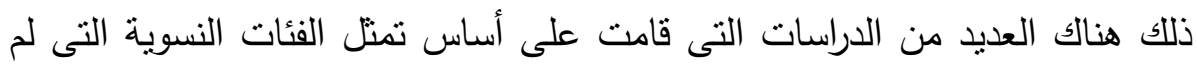

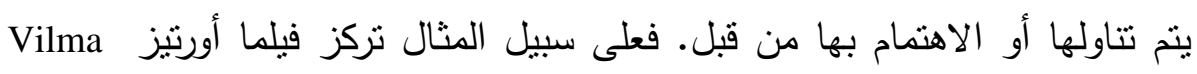
Ortiz

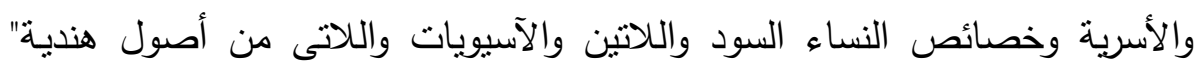

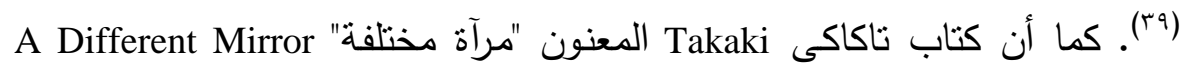

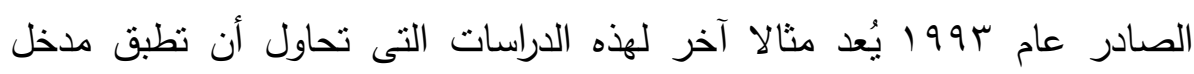

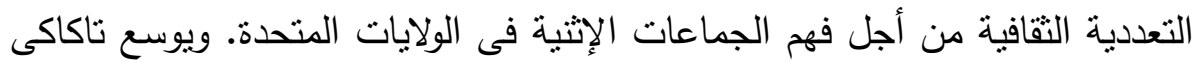

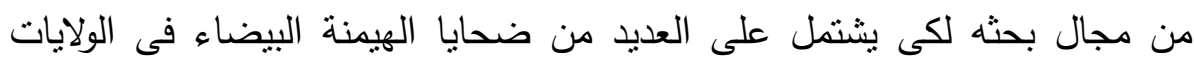

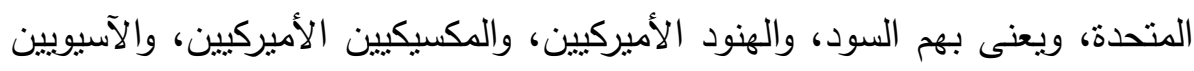

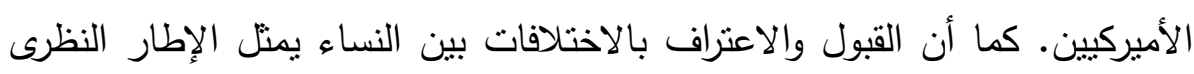

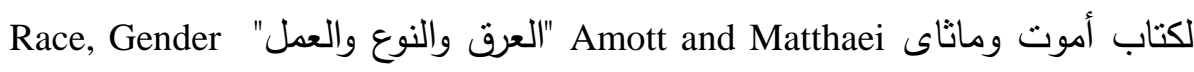


and Work

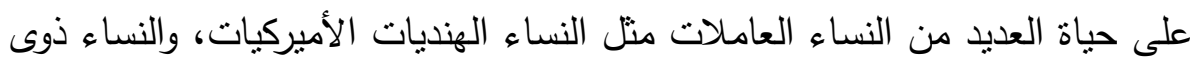

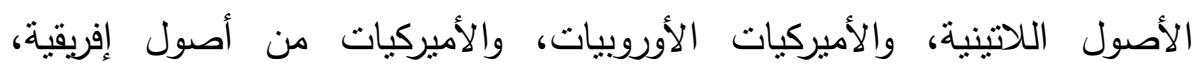
والأميركيات الآسيويات، والنساء البورتوريكات الأنوروبات

ومن خلا التركيز على النساء الملونات فإن هذا الدذل قد خلق نوعا جديدا

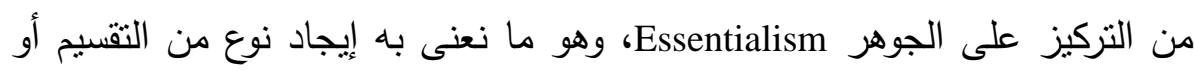

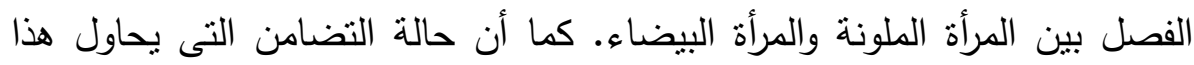

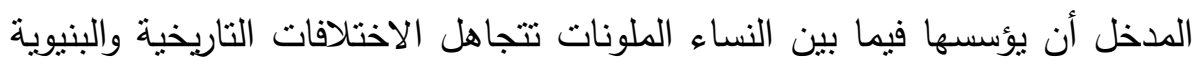

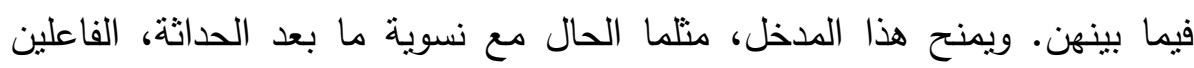

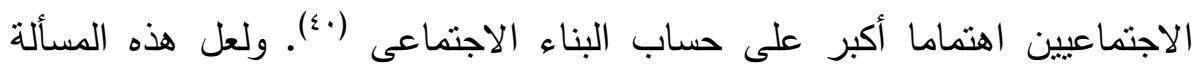

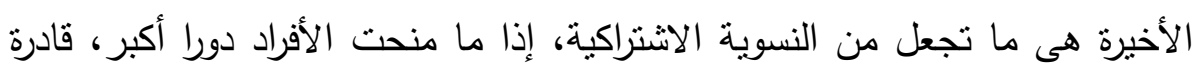

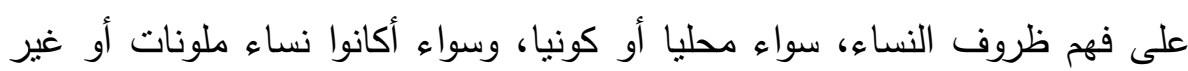
ذلك.

\section{Postmodern Feminism and بهوية مها بعد الصداثة والنظرية الغرائبية}

Queer Theory

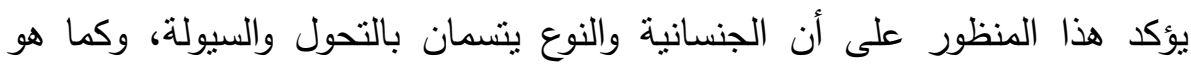

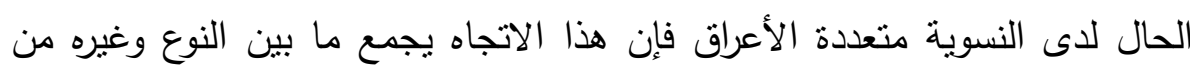
العناصر الاجتماعية مثل العرق والطبقة. وتقوض نسوية ما بعد الحداثة والنظرية الغرائبية تماسك النظام الاجتماعى الذى تم تأسيسه على اختلافات جنسية بين الرجل والمرأة، وعلى اختلافات النوع التى تحدد لكل منهما وظائف وأدوار اجتماعية محددة.

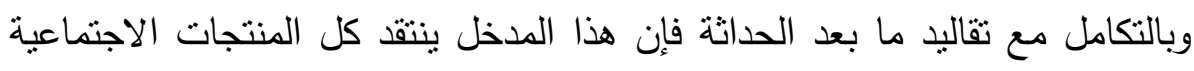

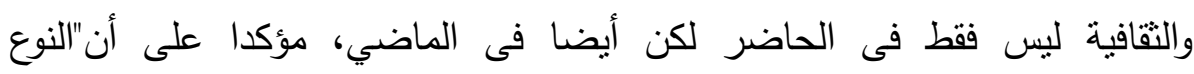

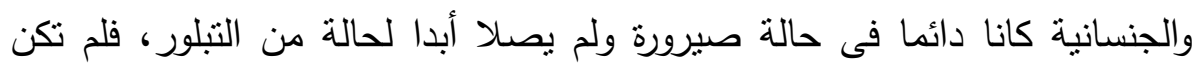
هناك أية هويات دائمة، وهو أمر جعل من سياسات الهوية محل نساؤل دائم" (1). 
ويعنى ذلك أن نلك المواضعات المتعارف عليها اجتماعيا والمقبولة ثقافيا هى من

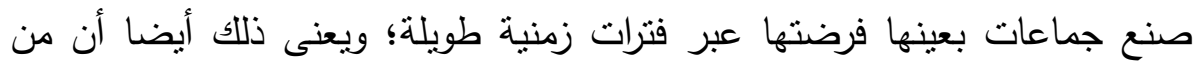
حقنا كجماعات وأفراد أن نرفض الهويات الهحددة لنا سلفا، وأن نروج لهوياتتا التى لنى نراها ونعيد صياغتها وفقا لأهوائنا وتطلعاتتا ورؤانا. وتعكر النظرية الغرائبية صفو ما اعتقدنا أنه عادى وطبيعي؛ ففى هذه النظرية تُبطل الثنائية الجنسية Bisexuality ما تم التعارف عليه من تقسيم جنسى بين الجنسية الغيرية Heterosexual والجنسية المتلية Homosexual، فالجسد يمكن أن فئن يكون أنثويا وذكوريا فى الوقت نفسه. وترى باكازين وآخرون Baca Zinn et al بأن ان المشكلة المرتبطة بكل من نسوية ما بعد الحداثة والنظرية الغرائية تكمن فى أنهما

ينتهيان بجعل النوع مجرد "نمط حياة ما بعد حداثى متعدد الأثكال والأوضاع" (rأ). وارتباطا مع التراث ما بعد الحداثي، فإن هذا الدذخل النسوى لا يقف كثيرا عند مسألة البناء الاجتماعى التى تؤيد الواقع المعيش من خلال جماعات اجتماعية

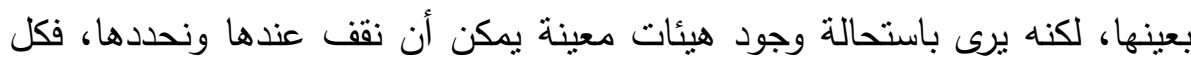
شىء قابل للاختلاف والتحول بما فى ذلك الجنس والنوع الذى فرضته ضوابط اجتماعية معينة. من هذا المنطلق فإن هذا الدذخل يضرب أفكار المجتمع الراسخة

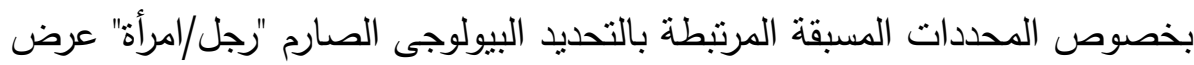
الحائط، ويرى، وبسبب وجود فئات جنسية جديدة مثل المنليين وذوى الجنس المتعدد والنساء المسترجلات، أن هذه التصنيفات المفروضة مجتمعيا تحتاج لمراجعات واسعة فى ضوء الهيئات الجنسية الجديدة المتشكلة. وإذا كان هذا الدذخل لا يعطى البناء الاجتماعى تلك الأهمية التى منحتها لأليا

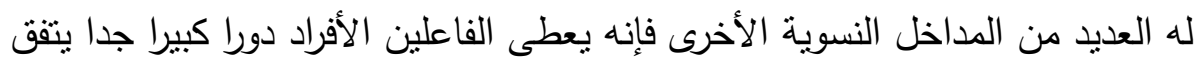

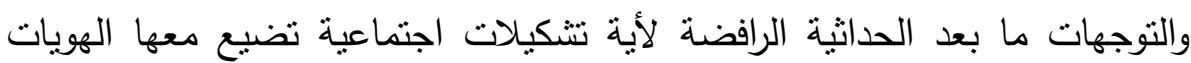
الفردية وشبه الفردية. فالأفراد وفقا لهذا الددخل هم من يحددون هوياتهم ويشكلونها لإنها

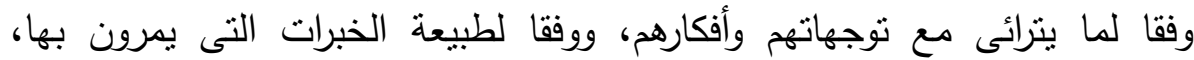


ومستوى الوعى الذى يصلون إليه عبر ممارسات الحياة اليومية، وعبر تناعلاتهم مع

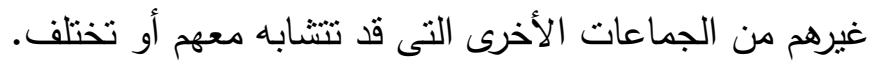

فى الواقع، وكما بينا سابقا، فإن كل نظرية أضافت إلى غيرها من النظريات بما

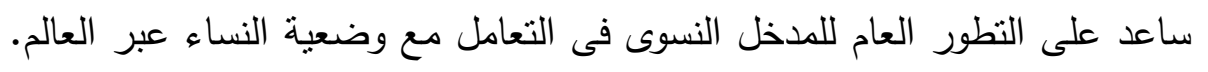

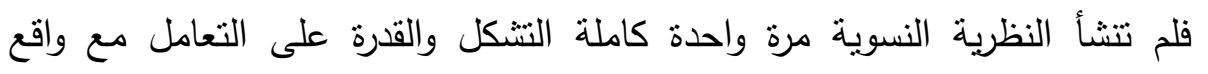
النساء، بل يمكن القول إنها تطورت وفقا للسياقات الاجتماعية والزمنية المختلفة، وبما

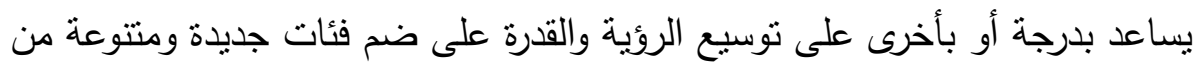
النساء المستلبات الحقوق اجتماعيا واقتصاديا وسياسيا.

لقد حاولت النظرية اللييرالية أن تحسن من ظروف النساء ضمن السياق العام

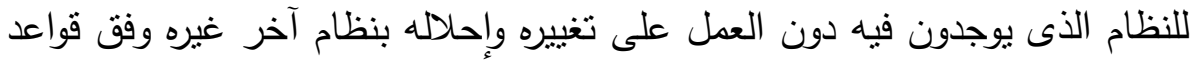
اجتماعية جديدة. كما حاولت أن تغير من ظروف القمع والاستغلال التى نواجهها

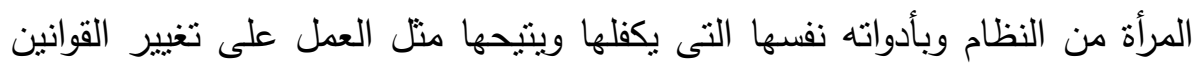
واستبدالها بغيرها، والتظاهر ، والعمل من خلال المنظمات غير الحكومية.

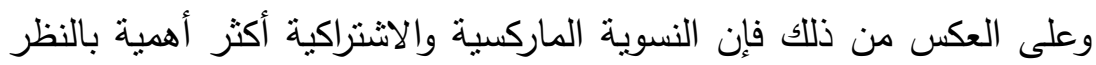

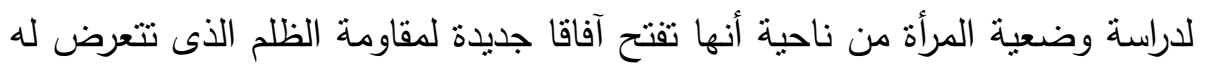

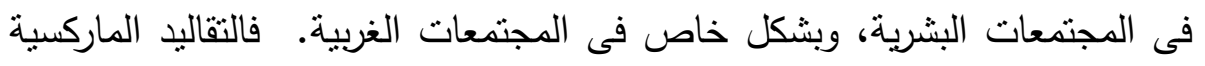

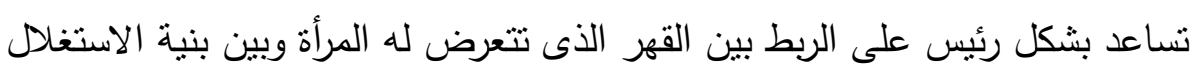

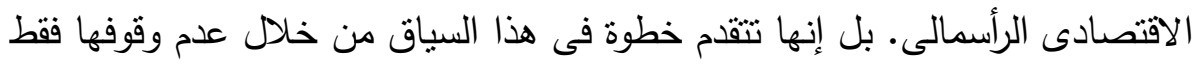

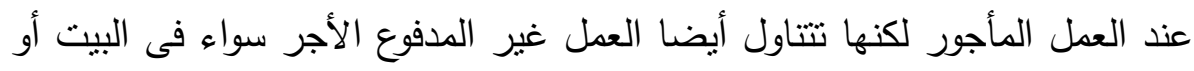

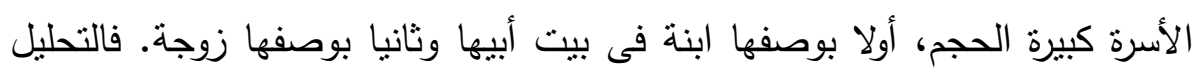

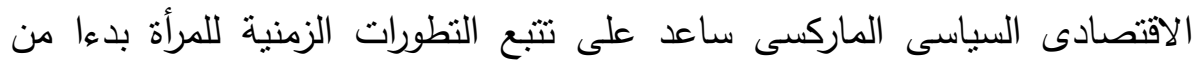

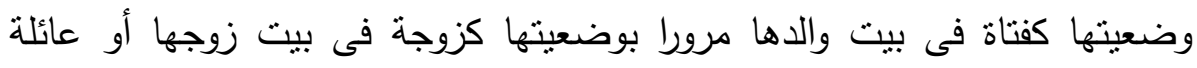

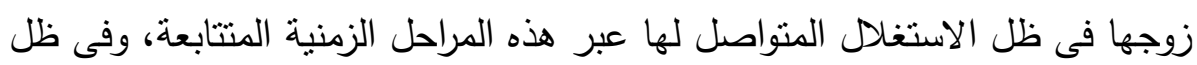


هدر عملها غير الددفوع الأجر. وفى الواقع فإن التحليل الطبقى الماركسى مازال

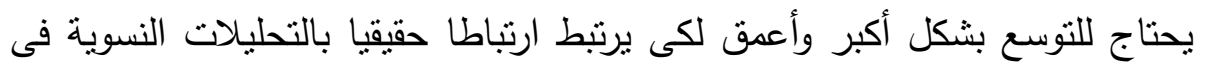

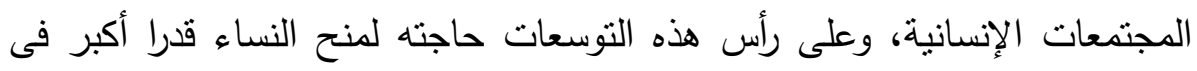
تحليلاته الطبقية منلما يمنحها للرجال؛ فالتحليل الطبقى فى الماركسية يبدو تحليلا ذكوريا أكثر منه تحليلا أنثويا.

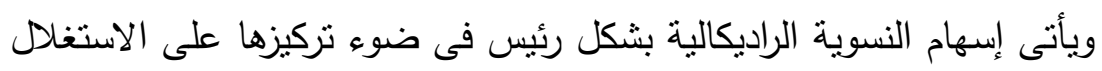

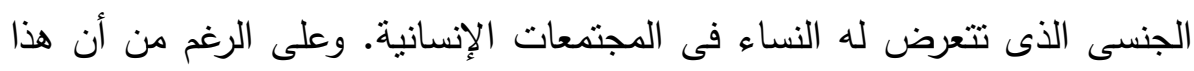
المدخل يضفى طابعا جوهريا Essentializes من خلال هذا التحليل الجنسى فإنه التهاته ليس بمقدور أحد أن يتجاهل أهمية الجنسانية فى تحديد خصائص العلاقة بين الرجال

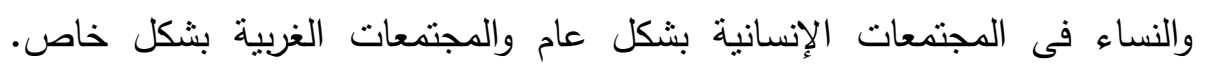
وارتباطا مع هذا الددخل يطالعنا مدخل وجهات النظر النسوية الذى تبرز الهئل الهيته

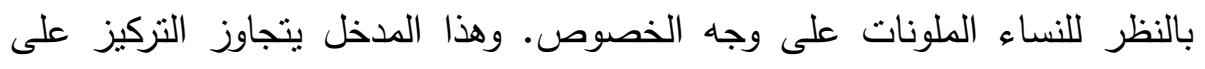

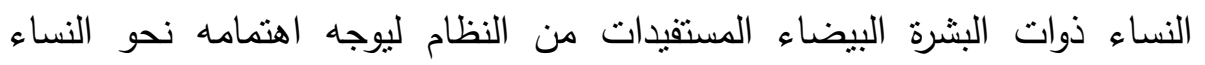

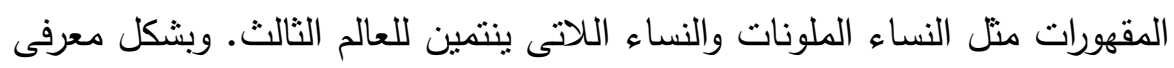

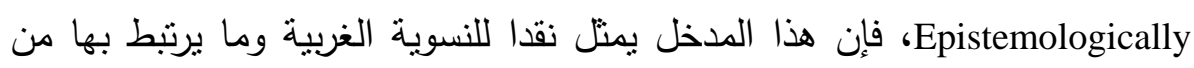

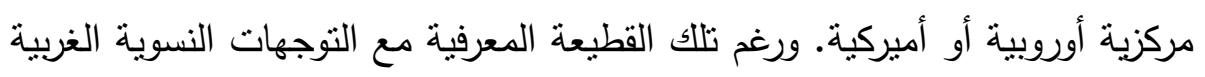

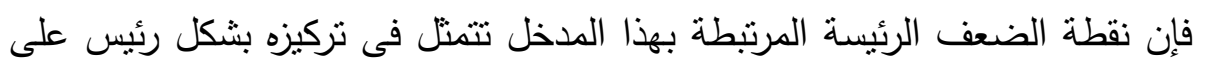

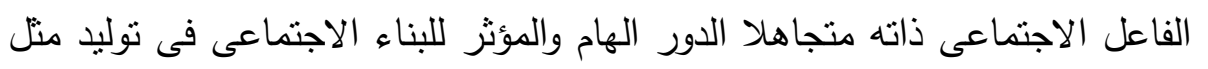
هذه الظروف المساعدة على قهرالنساء واستغلالكهن.

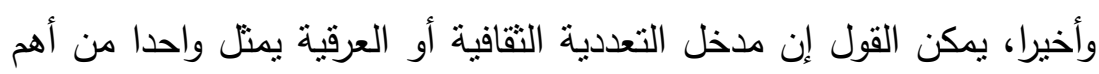

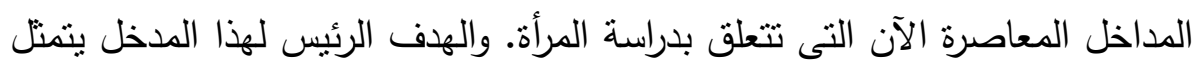

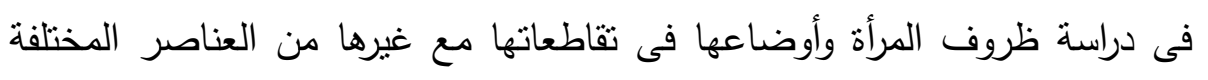

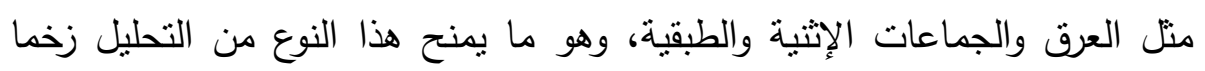
فكريا ونظريا بثرى النظرية النسوية ويعمق من قدراتها على فهم واقع المرأة المعيش. 
ومن وجهة نظرنا فإن مستقبل النظرية النسوية يعتمد بشكل كبير على مدى النجاح

الذى يحققه هذا المدخل فى دراسة أوضاع المرأة فى المجتمعات البشرية المختلفة.

والواقع أن هذه الاتجاهات النظرية المختلفة يمكن أن تساعد على تطوير واقع

المرأة فى العالم العربى، رغم اختلاف السياقات الحضارية بين الثرق والغرب، ورغم

وطأة التقاليد الجاثمة على واقع المرأة العربية. فما لا شك فيه أن التصورات الليبرالية

والماركسية يمكن أن تضيف مداخل مهمة وواعدة بالنظر لتحرير المرأة فكريا

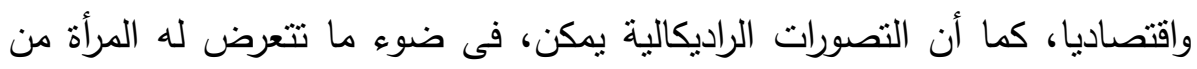

استلاب جنسى، أن نتير الطريق أمام صانع القرار من أجل مواجهة أى استغلال

جنسى يمكن أن تتعرض لله المرأة من خلال الضغوط الاجتماعية والثقافية التى التى

تتعرض لها. وأخيرا فإن مدخل التعددية التقافية يمكن أن يلعب دورا كبيرا فى تجسير

الفجوة بين الصفوات النسائية فى مجتمعاتتا العربية وبين المرأة العاملة والفقيرة

والريفية، بما يساعد على توسيع الفهم العميق لواقع المرأة العربية بمختلفة شرائحها

الاجتماعية المتباينة. ويمكن أن يتم ذلك فى توافق حقيقى ومتسامح مع الرؤى الدينية

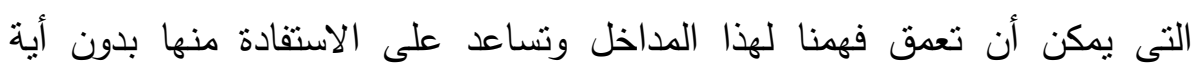

تعارضات مسبقة لها، وبدون فرض تصورات مثالية على واقع المرأة العربية.

\section{المراجع}

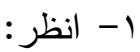

- Jaggar Alison M. and Rothenberg, Paula S., Feminist Frameworks: Alternative Theoretical Accounts of the Relations Between Women and Men, McGrawHill, New York, 1993, pp. 81-82.

- Chafetz, Janet Saltzman, Feminist Theory and Sociology Underutilized Contributions for Mainstream Theory, Annual Review of Sociology, Vol.23, 1997, p.97 (24).

- Amott Teresa and Mattheai, Julie Race, Class, Gender and Women's Work, In, Margaret Anderson and Patricia Hill Collins, (eds.), Race, Class, and Gender: An Anthology, Fourth Edition, Wadsworth Publishing Co., CA, Belmont, 2001, p. 236. 
- Ferree, Myra Marx; Lorboer Judith and Hess, Beth B. (eds.), Revisioning Gender, AltaMira Press, Walnut Creek. CA, 2001, pp. Xv-xvii.

- Eagleton, Mary (ed.), A Concise Companion to Feminist Theory, Blackwell, MA, 2003.

- Kolmar Wendy K. and Bartkowsk, Frances (eds.), Feminist Theory: A Reader, McGraw-Hill Higher Education, Boston, 2005.

- Walters, Margaret, Feminism: A Very Short Introduction, Oxford University Press, Oxford and New York, 2005.

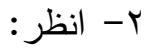

- McRobbie, Angela, The Aftermath of Feminism: Gender, Culture and Social Change, Sage, Los Angeles and London, 2009.

- Jessica, Valenti, Full Frontal Feminism: A Young Woman's Guide to Why Feminism Matters. Seal Press, USA, 2007.

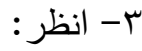

- Hannam, June Feminism, Harlow, England and New York, Pearson/ Longman, 2007.

$$
\text { ع }
$$

- Lorber, Judith Gender in Equality: Feminist Theories and Politics, Roxbury, LA, 1998, p. 28.

$$
\text { كما يمكن الرجوع لـ }
$$

- Beth Anne Shelton and Benn Agger, Shotgun Wedding, Unhappy Marriage, Non-Fault Divorce? Rethinking the Feminism-Marxism Relationship, pp. 2542, in, ed., Theory on Gender, Feminism on Theory, Aldine and Gruyter, New York, 1993.

- Lorber, 1998, op. cit, p.29.

$$
\text { 0 - 1 انظر }
$$

$$
\text { ר }
$$

- Kum-Kum Bhavnani, (ed.), Feminism and Race, Oxford University Press, Oxford and New York, 2001.

$$
\text { - - V }
$$

- Campbell Rebecca and Wasco, Sharon M., Feminist Approaches to Social Science: Epistemological and Methodological Tenets. American Journal of Community Psychology, Vol.28, Dec 2000, pp.773-791.

$$
\text { : انظر - 1 }
$$

- Lorber, 1998, op. cit, p.15.

$$
\text { 9-حول أوضاع المرأة فى الولايات المتحدة انظر : }
$$

- Teresa Amott and Julie Mattheai, Race, Gender and Work: Multicultural Economic History of Women in the United States, South End Press, Boston: MA, 1996. 


$$
\text { وحول أوضاع المرأة على مستوى كونى، انظر : }
$$

- Kathryn Ward, (ed.), Women Workers and Global Restructuring, ILR Press, Ithaca, NY, 1990.

- Hester Eisenstein, Feminism Seduced: How Global Elites Used Women's Labor and Ideas to Exploit the World, Paradigm Publishers, Boulder, 2009.

- Robin L. Riley; Chandra Talpade Mohanty and Minnie Bruce Pratt, Feminism and War: Confronting US Imperialism, Zed Books, London and New York, 2008.

- Valentine M. Moghadam, “Gender and the Global Economy”, pp. 128-160, in Myra Marx Ferree; Judith Lorber and Beth B. Hess, op. cit.

- Lisa D. Brush, "Gender, Work, Who Cares?! Production, Reproduction, Deindustrialization, and Business as Usual”, pp. 161-189, in Myra Marx Ferree; Judith Lorber and Beth B. Hess, 1998, op. cit.

- Debra B. Bergoffen, Paula Ruth Gilbert, Tamara Harvey and Connie L. McNeely, (ed.), Confronting Global Gender Justice: Women's Lives, Human Rights, Routledge, London and New York, 2011.

- McCann, Carole R. and Kim, Seung-kyung Feminist Theory Reader: Local and Global Perspective, Routledge, New York, 2003.

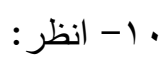

- Chafetz, Janet Saltzman Feminist Theory and Sociology Underutilized Contributions for Mainstream Theory, Annual Review of Sociology, Vol. 23, 1997, p. 97 (24).

- Hurst, Charles E. Social Inequality: Forms, Causes, and Consequences, $4^{\text {th }}$ ed, Allyn and Bacon, Boston and London, 2001.

$$
\text { : - (1) }
$$

- Mimi Abramovitz, Regulating the Lives of Women, Social Welfare Policy from Colonial Time to the Present, South End Press, Boston, MA, 1988.

- Chafetz, 1997, op.cit.

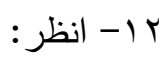

- England, Paula 1993, op. cit.

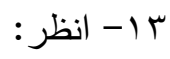

- Campbell Rebecca and Wasco Sharon M., 2000, op.cit.

$$
\text { وانظر أيضا: }
$$

- Acker, Joan “Class, Gender, and the Relation of Distribution.” Signs, 13 (3),

- 1988, pp. 473-497.

- Joan Acker, From Sex Roles to Gendered Institutions, Contemporary Sociology, Volume 21, Issue 5, Sept. 1992, pp. 565-569.

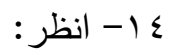

- Chafetz, Janet Saltzman, 1997, op.cit, p. 34

- Hurst, Charles E., 2001, op.cit, p. 85 
- Ibid, p.83.

$$
\text { : } 10
$$

\section{-}

$$
\text { : } 17
$$

- Pollert, Anna Gender and Class Revisited; or, the poverty of 'Patriarchy', Sociology, Vol. 30, No.4, Nov. 1996, p.639 (21).

- Charles E. Hurst, 2001, op. cit, p. 74.

- Paula England, 1993, op. cit, pp. 43-45.

- Jane C. Ollenburger and Helen A. Moore, (1992). A Sociology of Women, the Intersection of Patriarchy, Capitalism, and Colonization, Prentice Hall, Englewood Cliffs N.J., 1992, p. 18.

- Paula England, 1993, op. cit., pp. 43-45.

- Hester Eisenstein, Feminism Seduced: How Global Elites Used Women's Labor and Ideas to Exploit the World, Paradigm Publisher, Boulder, 2009.

- Myra Marx Ferree and Aili Mari Tripp, Global Feminism: Transnational Women's Activism, Organizing, and Human Rights, New York University Press, New York, 2006.

- Maria Mies, Patriarchy and Accumulation on a World-Scale: Women in the International Division of Labor, Zed Books, London and Atlantic Highlands, N.J., USA, 1986.

$$
\text { 1 ا- واردة فى : n }
$$

- Stromberg, Ann H. and Harkess, Shirley Women Working, $2^{\text {nd }}$ ed, Mayfield, CA, 1988, p. 130.

$$
\text { : } 19
$$

- Nakano Evelyn Glenn, From Servitude to Service Work: Historical Continuities in the Racial Division of Paid Reproductive Labor. Signs. Vol. 18, No. 1, Autumn 1992, p. 3

$$
\text { : r }
$$

- Lorber, 1998, op.cit, p. 62.

- Ibid, p. 66, 75, 83.

$$
\text { : انظر }
$$

وانظر أيضا :

- Jacqueline Rhodes, Radical Feminism, Writing, and Critical Agency: From Manifesto to Modem, State University of New York Press, Albany, 2005.

- Bottero,Wendy "Clinging to the Wreckage? Gender and the Legacy of Class”, Sociology, Vol.32, No.3, August 1998, p.469 (22).

- Barbara A. Crow, Radical Feminism: A Documentary Reader, New York University Press, New York, 2000.

$$
\text { : انظ }
$$

- Anderson, Margaret and Collins, Patricia Hill,2001, op. cit. p. 509. 
- Campbell ,Rebecca and Wasco, Sharon, M., 2000, op. cit.

$$
\text { r }
$$

- Campbell ,Rebecca and Wasco, Sharon, M., 2000, op. cit.

(n)

$$
\text { ع }
$$

- Maxine Baca Zinn, Pierrette Hondagneu-Sotelo and Michael A. Messner, Gender Through the Prism of Difference, p. 170, in Margaret L. Anderson and Patricia Hill Collins, op. cit.

- Chafetz, Janet Saltzman 1997, op. cit.

- Anna Pollert, Gender and Class Revisited; or, the poverty of 'Patriarchy', Sociology, Vol.30, No.4, Nov. 1996, p. 639 (21).

$$
\text { o }
$$

- Naomi Zack, Laurie Shrage and Crispin Sartwell,(eds), Race, Class, Gender, and Sexuality, the Big Questions, Blackwell, UK, Oxford, 1998.

- Lorber, 1998, op. cit., pp. 85-86.

$$
\text { רץ }
$$

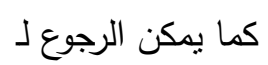

- Elizabeth Grosz in Naomi Zack, Laurie Shrage and Crispin Sartwell, op. cit, pp. 85-86.

- Lorber, 1998, op.cit., p. 116, 122, 126.

$$
\text { : انظر - rV }
$$

- Chafetz Janet Saltzman, 1997, op. cit.

$$
\text { : انظر }
$$

- Chafetz Janet Saltzman, 1997, op. cit.

$$
\text { : انظو }
$$

- Campbell Rebecca and Wasco, Sharon M., 2000,op. cit, p. 782.

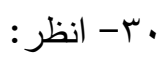

- Amin, Samir The Political Economy of the Twentieth Century, Monthly Review, Vol.52, I2, June 2000, p.1.

- Amin, Samir Imperialism and Globalization, Monthly Review, Vol.53, I2, June 2001, p.6.

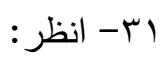

- Margaret L. Anderson and Patricia Hill Collins, op. cit., p. 169.

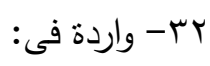

- Ferree, Myra Marx; Lorboer Judith and Hess, Beth B., 2001, op. cit. pp. 128160 .

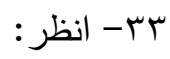

- Anderson, Margaret L. and Collins, Patricia Hill, 2001, op. cit., p. 169. 


$$
\text { ع آ- انظر : }
$$

- Judith Lorber,1998,op. cit., p. 13.

- Maxine Baca Zinn and Bonnie Thornton Dill, (eds.), Women of Color in U.S. Society, Temple University Press, Philadelphia, 1994, p. 11.

- Aguirre, A. and J. H. Turner, American Ethnicity, McGraw Hill, Boston, Mass,1998.

- Elizabeth Ann Bartlett and Rebellious, Feminism: Camus's Ethic of Rebellion and Feminist Thought, Palgrave Macmillan, New York, 2004.

$$
\text { هץ- انظر : }
$$

- Lorber, 1998, op. cit., p. 134

- Ferree, Myra Marx Lorber Judith and Hess, Beth B. 2001, op. cit, p. xvii.

$$
\text { צب- انظر : }
$$

- Anderson, Margaret L. and Collins, Patricia Hill, 2001, op. cit., p. 4.

- Maxine Baca Zinn and Bonnie Thornton Dill, 1994, op. cit., p. 6

- Chafetz Janet Saltzman, 1997, op. cit.

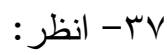

- Maxine Baca Zinn and Bonnie Thornton Dill, 1994, op. cit., pp. 138-139.

$$
\text { مץ- انظر : }
$$

- Anderson, Margaret L. and Collins, Patricia Hill, 2001, op. cit., p. 14

$$
\text { q ب- انظر : }
$$

- Maxine Baca Zinn and Bonnie Thornton Dill, 1994, op. cit., p. 13.

- Maxine Baca Zinn and Bonnie Thornton Dill, Theorizing Difference from Multicultural Feminism, Feminist Studies. Vol.22, No.2, Summer 1996, pp. 322-323.

$$
\text { . }
$$

- Adkins Lisa and Skeggs, Beverley Feminism after Bourdieu, Blackwell Publishing, Oxford: UK and Malden: MA, 2004.

- Lorber, 1998, op. cit., p. 188.

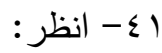

$$
\text { r }
$$

- Anderson, Margaret L. and Collins, Patricia Hill, 2001, op. cit., p. 174. 


\section{Abstract \\ FEMINIST THEORY AND THE STUDY \\ OF SOCIAL INEQUALITY}

Saleh Soliman

The main target of this research is to identify the different feminist theories in their relation with handling social inequalities experienced by women in human societies. It also tries to classify feminist theories since its beginning till now. The classification process combines both simplicity and depth. Here simplicity means the clarity of classifying feminist theories since 1960s till now and depth means presenting the important elements of these theories. The research ends with three main theoretical approaches which include: gender reform feminism, gender resistance feminism and gender rebellion feminism. 
ru 